\title{
Partial melting of a C-rich asteroid: Lithophile trace elements in ureilites.
}

\author{
by \\ Jean-Alix Barrat ${ }^{1}$, Albert Jambon ${ }^{2}$, Akira Yamaguchi ${ }^{3}$, \\ Addi Bischoff ${ }^{4}$, Marie-Laure Rouget ${ }^{5}$, and Céline Liorzou ${ }^{1}$
}

1: Université de Bretagne Occidentale, Institut Universitaire Européen de la Mer, CNRS UMR 6538, Place Nicolas Copernic, 29280 Plouzané, France. E-mail : barrat@univ-brest.fr

2: Sorbonne Universités, UPMC Univ Paris 06, UMR 7193, Institut des Sciences de la Terre Paris (iSTeP), F-75005 Paris, France.

3: National Institute of Polar Research, Tachikawa, Tokyo 190-8518, Japan and Department of Polar Science, School of Multidisciplinary Science, Graduate University for Advanced Sciences, Tachikawa, Tokyo 190-8518, Japan

4: Institut für Planetologie, Westfälische Wilhelms-Universität Münster, Wilhelm-Klemm-Str. 10, 48149 Münster, Germany.

5: Université de Bretagne Occidentale, Institut Universitaire Européen de la Mer, CNRS UMS 3113, Place Nicolas Copernic, 29280 Plouzané Cedex, France.

Keywords: trace elements, achondrite, ureilite, partial melting

submitted to Geochimica et Cosmochimica Acta, 27/04/2016

revised manuscript, 25/08/2016 


\begin{abstract}
Ureilites are among the most common achondrites and are widely believed to sample the mantle of a single, now-disrupted, C-rich body. We analyzed 17 ureilite samples, mostly Antarctic finds, and determined their incompatible trace element abundances. In order to remove or reduce the terrestrial contamination, which is marked among Antarctic ureilites by light-REE enrichment, we leached the powdered samples with nitric acid. The residues display consistent abundances, which strongly resemble those of the pristine rocks. All the analyzed samples display light-REE depletions, negative Eu anomalies, low $\left(\mathrm{Sr} / \mathrm{Eu}^{*}\right)_{\mathrm{n}}$, and $\left(\mathrm{Zr} / \mathrm{Eu}^{*}\right)_{\mathrm{n}}$ ratios which are correlated. Two groups of ureilites (groups A and B) are defined. Compared to group A, group B ureilites, which are the less numerous, tend to be richer in heavy REEs, more light-REE depleted, and display among the deepest $\mathrm{Eu}$ anomalies. In addition, olivine cores in group B ureilites tend to be more forsteritic $(\mathrm{Mg} \#=81.9-95.2)$ than in group A ureilites $(\mathrm{Mg} \#=74.7-86.1)$. Incompatible trace element systematics supports the view that ureilites are mantle restites. REE modelling suggests that their precursors were rather REE-rich (ca. 1.8-2 x CI) and contained a phosphate phase, possibly merrillite. The REE abundances in ureilites can be explained if at least two distinct types of magmas were removed successively from their precursors: aluminous and alkali-rich melts as exemplified by the Almahata Sitta trachyandesite (ALM-A), and Al and alkali-poor melts produced after the exhaustion of plagioclase from the source. Partial melting was near fractional (group B ureilites, which are probably among the least residual samples) to dynamic with melt porosities that did not exceed a couple of percent (group A ureilites). The ureilite parent body (UPB) was almost certainly covered by a crust formed chiefly from the extrusion products of the aluminous and alkali-rich magmas. It is currently uncertain whether the $\mathrm{Al}$ and alkali-poor melts produced during the second phase of melting reached the surface of the body. The fact that initial silicate melting of ureilitic precursors would have produced relatively low density liquids capable of forming an external crust to the UPB casts doubt on models that invoke chondritic outer layers to achondritic asteroids.
\end{abstract}




\section{Introduction}

The early history of the Solar System was marked by the accretion of numerous asteroid-sized bodies (large asteroids and embryos). Many of them underwent rapid internal heating, leading to melting and subsequent differentiation. Among the most significant issues for understanding the differentiation of rocky bodies are the exact processes of melting, the compositions of the generated magmas and how these were then segregated from their sources. Melt migration may have involved ascent to the surface to form a crust, or alternatively escape to space by explosive volcanism. It has recently been argued that partial melting of carbonaceous chondrite-like bodies (e.g. CV or CM), could have produced melts too dense to erupt through buoyancy alone. Consequently, the differentiation of such bodies could have generated distinctive internal structures, with a preserved chondritic carapace at the surface covering an igneous layer, and possibly a metallic core at their centers (Weiss and Elkins-Tanton, 2013; Fu and Elkins-Tanton, 2014). If true, these bodies could have harbored magnetic dynamos when their cores were still molten. The discovery that some $\mathrm{CM}$ and $\mathrm{CV}$ chondrites recorded ancient magnetic fields has strengthened such a view, although the origin of these fields, whether internal or linked to an early stage of solar activity, remains a matter for debate (e.g. Carporzen et al., 2011; Cournède et al., 2015).

The structure and differentiation history of C-rich bodies can be studied directly using meteorite samples. Unfortunately, no representative sampling of a single body, i.e. from the core to the crust, is currently available. However, the ureilites, one of the largest families of achondrites (ca. 400 different meteorites and $17 \%$ of the known achondrites currently reported in the Meteoritical Bulletin Database), represent a unique collection from the mantle of a single, now-disrupted, C-rich body (Downes et al., 2008). These rocks are coarse-grained peridotites, consisting chiefly of olivine and pyroxene (pigeonite, and more rarely augite and orthopyroxene), abundant carbon (up to $7 \mathrm{wt} \%$, graphite and diamond), with accessory metal and sulfides (e.g., Mittlefehldt et al., 1998). It is noteworthy that these peridotites are virtually devoid of feldspar.

Ureilites have been the focus of many geochemical studies. Even though uncertainties remain concerning the differentiation of the UPB, thermal modeling and extinct isotope systematics make it possible to reconstruct its overall history (e.g., Wilson et al., 2008; Budde et al., 2015; Goodrich et al., 2015). It accreted no more than 1.6 Ma after CAIs, i.e. later than the parent bodies of the magmatic irons, and about half a million years before most of the chondrite parent bodies. The UPB was definitely C-rich, but was isotopically distinct from the carbonaceous chondrites (Yamakawa et al., 2010; Warren, 2011). However, it contained enough ${ }^{26} \mathrm{Al}$ to be heated by the decay of this isotope, which allowed the segregation of S-rich metallic melts (e.g., Warren et al., 2006; Rankenburg et al., 2008; Budde et al., 2015), more likely before the onset of silicate melting (Barrat et al., 2015). Subsequent extraction of silicate melts is demonstrated by the presence of feldspar-rich rock debris in ureilitic breccias (e.g., Ikeda et al., 2000; Cohen et al., 2004; Bischoff et al., 2014), but the melting experienced by the UPB was more limited than in other early bodies, 
such as the angrite parent body or Vesta, where magma oceans homogenized the $\mathrm{O}$ isotope compositions (Greenwood et al., 2005). Indeed, ureilites display a wide range of $\Delta^{17} \mathrm{O}$ values which are well correlated with various mineral compositions (Clayton and Mayeda, 1996, and Fig. 1). Systematics of short-lived isotopes $\left({ }^{53} \mathrm{Mn}-{ }^{53} \mathrm{Cr},{ }^{182} \mathrm{Hf}-{ }^{182} \mathrm{~W},{ }^{26} \mathrm{Al}-{ }^{26} \mathrm{Mg}\right)$ indicate that the differentiation occurred between 3 and $7 \mathrm{Ma}$ after the CAIs (Yamakawa et al., 2010; Goodrich et al., 2010, Bischoff et al., 2014; Budde et al., 2015). It stopped soon after, with the catastrophic breakup of the body following a large impact, while its mantle was still hot.

Although it is now widely accepted that most ureilites are mantle restites (e.g., Boynton et al., 1976; Takeda, 1987; Warren and Kallemeyn, 1992; Scott et al., 1993; Warren et al., 2006; Goodrich et al., 2015 among others), the melting processes and the involvement of $\mathrm{C}$ during their formation are matters of intense debate. During the ureilite disruption event, $\mathrm{C}$ locally reduced olivine crystals, and produced their distinctive iron-depleted rims and veins (e.g., Miyamoto et al., 1985). Except for these rims and veins, olivines are quite uniform in $\mathrm{Mg} \#$ number $[=100 \mathrm{Mg} /(\mathrm{Mg}+\mathrm{Fe})$, atomic] within any given ureilite. However, between different samples their compositions display a huge variation, as shown by the olivine-core $\mathrm{Mg \#} \mathrm{(=forsterite} \mathrm{content),}$ which range from 74 to 97 . The Fe/Mn ratios (ranging from 3 to 57) are correlated with this parameter (e.g., Clayton and Mayeda, 1996; Mittlefehldt et al., 1998, Fig. 1). A similar relationship is also shown by pyroxenes, which are in equilibrium with the olivines. It has been often proposed that varying degrees of partial reduction coincident with partial melting (a process named "smelting") produced the range of olivine (and pyroxene) core compositions, from an initial proto-ureilitic material, displaying a near-uniform olivinecore Mg\# number (e.g., Goodrich, 1992; Singletary and Grove, 2003). Alternatively, the diversity of the silicate compositions could be inherited from the pre-igneous (nebular) history of the accreted materials [see Warren and Huber (2006), Warren (2012) and Goodrich et al. (2007, 2013a) for extensive discussions of these models].

In this paper, we report on trace element abundances obtained by Inductively Coupled Plasma Mass Spectrometry (ICP-MS) of a suite of unbrecciated ureilites. Our aim is to evaluate the full range of refractory lithophile element distributions displayed by these meteorites, in order to model the partial melting processes that occurred in the mantle of the ureilite parent body (UPB) and to discuss the diversity of the melts and also the possible structure of this C-rich body.

\section{Samples and analytical procedures}

We analyzed 15 Antarctic ureilites kindly provided by the NASA meteorite working group (MWG) and the National Institute of Polar Research (NIPR), and an additional 2 from the Sahara. The details of the meteorite samples used in this study are given in Table 1. These samples are among the least weathered ureilitic finds and their olivine cores cover nearly the full range of compositions known for these meteorites $(\mathrm{Fo}=74$ to $95 \%)$. One of the samples is anomalous. Unlike other samples which are peridotites, MET 
01085 is a pyroxenite devoid of olivine. Notice that we do not include in our study polymict ureilites nor samples of the rare "Hughes" group ureilites.

Fragments were crushed to a fine powder using a boron carbide mortar and pestle. Splits of the powders (typically $200-250 \mathrm{mg}$ ) were leached in $4 \mathrm{M} \mathrm{HNO}_{3}$ at room temperature during 30 minutes ("R1" residues; two distinct splits of GRO 95575 were independently leached) before dissolution. A subsample of NWA 8049 ("R2" residue) was leached for 90 minutes under the same conditions in order to evaluate the effects of a longer leaching duration. MET 01085, which is devoid of olivine, was leached at $120{ }^{\circ} \mathrm{C}$ during 30 minutes ("R3" residue). Residues were rinsed twice in ultrapure water and dried before weighing. Powders (unleached powders and residues) were digested by sequential mixtures of $\mathrm{HF} / \mathrm{HNO}_{3}, \mathrm{HNO}_{3}$ and $\mathrm{HCl}$. Elemental abundances were determined using a high-resolution inductively coupled plasma-mass spectrometer Thermo Element 2 at Institut Universitaire Européen de la Mer (IUEM), Plouzané, following a well-established procedure (e.g., Barrat et al., 2012). For the residues, Rare Earth Elements (REE) were separated and concentrated (Barrat et al., 1996) in order to improve the quality of the analyses. Results on international standards (BCR-2, BIR-1, WS-E, Allende USNM 3529, UB-N, PCC-1) have been repeatedly reported (Barrat et al., 2012, 2014, 2016). Based on standards and many sample duplicates, the precisions for abundances and trace element ratios [e.g., Eu/Eu*, where $\mathrm{Eu}^{*}$ is the expected Eu concentration for a smooth CI-normalized REE pattern, such that $\mathrm{Eu}_{\mathrm{n}}=\left(\mathrm{Sm}_{\mathrm{n}} \mathrm{x} \mathrm{Gd}_{\mathrm{n}}\right)^{1 / 2}$ ] are in most cases much better than $5 \%$ [two relative standard deviations $(2 \times \mathrm{RSD})]$.

\section{Results}

Analysis of the seventeen ureilites examined in this study involved three ICP-MS runs per sample: one complete run for each unleached and leached aliquot, and a supplementary one for each leached aliquot after REE separation and concentration, which always confirmed the previous complete run. The results are given in Table 2. For the leached samples (samples "R" in table 2), the reported REE abundances are those obtained after separation.

Our results are in good agreement with literature values (e.g., Boynton et al., 1976; Goodrich et al., 1991; Spitz and Boynton, 1991; Warren and Kallemeyn, 1992; Warren et al., 2006; Friedrich et al., 2010; Barrat et al., 2016). Peridotites are poor in lithophile trace elements, and ureilites are no exception. However, they display a wide range of abundances for these elements, as exemplified by La ranging from 0.28 to 22.6 $\mathrm{ng} / \mathrm{g}$ in the unleached samples. Results obtained with the leached samples duplicate those obtained with the unleached samples for most of the determined elements. The rational for leaching the sample powders was to remove or reduce any traces of terrestrial alteration they might contain, particularly for the light-REE elements, and this point is discussed further below. A direct examination of Table 2 shows that $\mathrm{Li}, \mathrm{Sc} \mathrm{Ti}, \mathrm{V}$, $\mathrm{Zn}, \mathrm{Zr}, \mathrm{Y}$ and heavy REEs concentrations are very similar in the unleached and leached aliquots. $\mathrm{P}, \mathrm{Ga}, \mathrm{Cu}$, $\mathrm{Rb}, \mathrm{Sr}, \mathrm{Cs}$ and light REE abundances are sometimes lower in the leached samples, and this could reflect either preferential dissolution of phases by $\mathrm{HNO}_{3}$ (e.g., sulfides for $\mathrm{Cu}$, schreibersite for $\mathrm{P}$ ) or removal of a 
terrestrial contaminant (e.g., La, Ce and $\mathrm{Sr}$ ), possibly scavenged by the secondary Fe-hydroxides or adsorbed by the interstitial, fine-grained, C-rich material (Guan and Crozaz, 2000). In the following sections, we will focus our discussion on the classical incompatible trace elements.

\section{Discussion}

\subsection{Fingerprints of terrestrial weathering and how to remove them in ureilites}

The low incompatible trace element abundances found in ureilites make them especially sensitive to terrestrial weathering.

Indeed, many ureilites display marked light REE enrichments and distinctive V-shaped REE patterns (Fig. 2a) that indicate the involvement of components enriched in light REE, which were first thought to be indigenous to the ureilite parent body (e.g., Boynton et al., 1976), but were more likely introduced into the rocks during terrestrial residence (e.g., Guan and Crozaz, 2000). Two falls in particular display V-shaped REE patterns: Novo Urey (Boynton et al., 1976) and Haverö (Wänke et al., 1972). However, Novo Urey was not collected immediately after its fall, and terrestrial contamination easily explains its light-REE enrichment (Guan and Crozaz, 2000). The case of Haverö is more ambiguous because this meteorite was recovered shortly after its fall. One may suggest that it contains minute amounts of an indigeneous light-REE rich phase, such as titanite. Such light-REE rich phases are exceptional in ureilites (Guan and Crozaz, 2000), and this hypothesis is unlikely at best. Only $70 \mathrm{ng} / \mathrm{g}$ of La were measured in Haverö by Wänke et al. (1972), and we believe that contamination during the handling and processing of the meteorite is a more probable explanation.

The secondary light-REE enriched components can be removed in Antarctic ureilites by $\mathrm{HNO}_{3}$ (e.g., Boynton et al., 1976; Spitz and Boynton, 1991). Leaching procedures are difficult to test for samples available in very small quantities: if the leaching is too weak, the secondary component is not totally eliminated; if the leaching is too strong, the compositions of the residues could be controlled by those of the most resistant phases, and could be very different to those of the pristine rocks. Because our allocated samples were small, it was not possible to completely evaluate the effectiveness of the various leaching procedures. After a few preliminary tests using strongly weathered Saharan ureilites, we concluded that a leaching step with $4 \mathrm{~N} \mathrm{HNO}_{3}$ for half an hour at room temperature, does not alter the pyroxene/olivine ratios in the residues, and so provides satisfactory results. The lithophile trace element abundances of the residues are often very similar to those of the unleached samples but the irregularities displayed by the REE patterns of the unleached samples (e.g., the Ce anomalies, see Fig. 2a) are erased or reduced. As exemplified by NWA 8049, a longer leaching duration does not produced very different results, and seems unnecessary (Table 2).

For each sample, the residues display lower $\mathrm{La} / \mathrm{Sm}$ ratios than the unleached powders, which indicates that all the samples contained traces of a secondary light-REE enriched components (Fig. 2b). Only two 
residues (ALH 81101 R1 and LAP 03587 R1) display patterns with slight La or Ce irregularities, suggesting a "residual" contribution of secondary light-REE enriched components, which should not be overemphasized. It is important to note that ureilites do not contain phosphates. P is largely controlled by phosphides that are devoid of REEs. The partial dissolution of phosphides by $\mathrm{HNO}_{3}$ (Table 2), has obviously no impact on the incompatible trace element abundances of interest, except of course for P. The situation would be different for phosphate-bearing achondrites for which such a leaching procedure is not suitable and is not recommended. We leached MET 01085 more severely because this rock is a pyroxenite and the possible preferential dissolution of olivine was not a problem.

The lithophile trace element abundances of the residues are certainly very close to those of the pristine ureilites. Indeed, the REE abundances in the residues are very similar to those measured in the fresh Almahata Sitta ureilites (Fig. 3). Only these data and the P abundances of the unleached fractions will be used in the following sections and drawn in the various figures. In contrast with Antarctic samples, the hot desert finds contained secondary phases such as barite, which are not easily leachable and account for high $\mathrm{Ba}$ and $\mathrm{Sr}$ abundances and sometimes anomalous REE distributions (e.g., Barrat et al., 2010). Therefore, only two mildly weathered Saharan ureilites were selected for this study.

\subsection{Diversity of incompatible trace element abundances and ratios in ureilites}

The diversity of the trace element abundances in ureilites are well illustrated by their trace element patterns normalized to CI (Figs. 3 and 4). The range of abundances is huge, with values that are spread over two orders of magnitude for the most incompatible elements (e.g., Rb, Ba, La). The REE patterns display variable light REE depletions [e.g., $(\mathrm{La} / \mathrm{Sm})_{\mathrm{n}}=0.022-0.65,(\mathrm{Pr} / \mathrm{Sm})_{\mathrm{n}}=0.11-0.73$ ] and heavy-REE enrichments $\left[(\mathrm{Dy} / \mathrm{Lu})_{\mathrm{n}}=0.18-0.62\right]$ and always show marked negative $\mathrm{Eu}$ anomalies $\left(\mathrm{Eu} / \mathrm{Eu}^{*}=0.14-0.68\right)$. These anomalies are accompanied by low $\mathrm{Zr} / \mathrm{Eu}^{*}$ and $\mathrm{Sr} / \mathrm{Eu}^{*}$ ratios $\left[\left(\mathrm{Zr} / \mathrm{Eu}^{*}\right)_{\mathrm{n}}=0.03-0.75,\left(\mathrm{Sr} / \mathrm{Eu}^{*}\right)_{\mathrm{n}}=0.08-0.60\right.$, except NWA 8049 whose $\mathrm{Sr} / \mathrm{Eu}^{*}$ ratio is explained by hot desert weathering]. Interestingly, a positive Eu anomaly and high $(\mathrm{Sr} / \mathrm{Eu} *)_{\mathrm{n}},\left(\mathrm{Zr} / \mathrm{Eu}^{*}\right)_{\mathrm{n}}$ ratios were previously observed in ALM-A, a trachyandesitic clast collected in the Almahata Sitta strewnfield (Bischoff et al., 2014).

The trace element patterns allow us to distinguish two groups of ureilites. The first group (group A) comprises: A 881931, ALH 77257, ALH 81101, EET 96042, GRA 95205, GRO 95575, LAP 03587, PCA 82506, Y 790981, Y 981810 and NWA 8049. The second group (group B) comprises: ALH 82130, EET 83225, LAR 04315, Y 791538, and NWA 7686. Compared to group A, group B ureilites tend to be richer in heavy REEs, more light-REE depleted, and display among the lowest $\left(\mathrm{Sr} / \mathrm{Eu}^{*}\right)_{\mathrm{n}},\left(\mathrm{Zr} / \mathrm{Eu}^{*}\right)_{\mathrm{n}}$ ratios and deepest $\mathrm{Eu}$ anomalies. This separation in to two groups may appear somewhat arbitrary as the range of their respective trace element ratios display some overlap (e.g., Fig. 5). Nonetheless, the ureilites from these two groups are well separated in a $(\mathrm{Dy} / \mathrm{Lu})_{n}$ vs. Eu/Eu* plot (Fig. 5) or in $(\mathrm{Pr} / \mathrm{Sm})_{n}$ or Eu/Eu* vs. Sm plots (Fig. 6). The MET 01085 pyroxenite exhibits a trace element pattern very similar to the group B ureilites, and so is most likely a member of this group. 
The $\mathrm{Eu} / \mathrm{Eu}^{*},\left(\mathrm{Sr} / \mathrm{Eu}^{*}\right)_{\mathrm{n}}$ and $\left(\mathrm{Zr} / \mathrm{Eu}^{*}\right)_{\mathrm{n}}$ ratios are strongly correlated. In $\left(\mathrm{Sr} / \mathrm{Eu}^{*}\right)_{\mathrm{n}}$ and $\left(\mathrm{Zr} / \mathrm{Eu}^{*}\right)_{\mathrm{n}} \mathrm{vs}$. $\mathrm{Eu} / \mathrm{Eu}^{*}$ plots, our analyses display well defined trends which can be extended through the chondritic reference and up to ALM-A (Fig. 5). Similarly, the Eu anomalies of the ureilites are well correlated with their light-REE depletions, and a clear trend is obtained in a $(\mathrm{Pr} / \mathrm{Sm})_{\mathrm{n}} \mathrm{vs} \mathrm{Eu} / \mathrm{Eu}^{*}$ plot, that extends to the chondritic ratios but not to ALM-A. The behavior of the heavy REEs seems more complex and a broad trend is only obtained for the group A ureilites in a $(\mathrm{Dy} / \mathrm{Lu})_{\mathrm{n}} \mathrm{vs}$. Eu/Eu* plot (Fig. 5). We noticed that the poorer a ureilite is in incompatible trace elements (as exemplified by Sm), the more it is enriched in heavy-REE (Fig. 6). No relationships are evident between Eu-anomalies, light-REE depletions and incompatible trace element abundances (Fig. 6). Collectively, these observations support the view that the ureilites represent mantle restites, but also point to the complexity of the melting and melt segregation processes, which can be further evaluated using trace element systematics.

\subsection{Partial melting in the UPB body}

Various partial melting models have been tentatively proposed to explain the REE abundances of ureilites (e.g., Warren and Kallemeyn, 1992; Goodrich et al., 2007), but these do not provide a good match for the fine structures the REE patterns (see Fig. 16 in Goodrich et al., 2007).

The recent discovery of felsic brachinites (Day et al., 2009), suggests that the crust of many small differentiated bodies could have been silica-rich instead of basaltic, as previously thought. Furthermore, recent experimental studies have shown that at low $\mathrm{fO}_{2}$ conditions (i.e., at $\mathrm{IW}$ or below), partial melting of a chondritic protolith can generate magmas characterized by high alkali and silica contents (Gardner-Vandy et al., 2014; Usui et al., 2015). Seen in this light, the feldspathic debris found in polymict ureilites (e.g., Ikeda et al., 2000; Cohen et al., 2004), and more importantly the discovery of a "large" ureilitic trachyandesite (Bischoff et al., 2014) demonstrate that such magmas were generated by the melting of the UPB. Indeed, as pointed out by Goodrich and Wilson (2013), the early magmatism produced on the UPB could have been largely trachyandesitic. The extraction of these melts from chondritic precursors would yield residues with low alkalis and superchondritic $\mathrm{Ca} / \mathrm{Al}$ ratios, precisely matching some of the distinctive chemical features observed in the ureilites.

Assuming a chondritic composition for the UPB, we propose that its melting history can be summarized as having taken place in three principal stages:

a/ melting of the sulfides at a temperature close to the troilite-metal eutectic and segregation of a small $S$-rich core before the onset of significant silicate melting; this step is required to explain the average $\delta^{56} \mathrm{Fe}$ of the ureilites, that is significantly higher than that of chondrites (Barrat et al., 2015); it is in agreement with the marked S-depletions and the siderophile element abundances of the ureilites (e.g., Warren et al., 2006); 
this step would not have had an impact on the incompatible trace element distributions which are neither chalcophile nor siderophile. After core segregation, the ureilite precursors would have displayed flat REE patterns, but their incompatible trace element abundances were likely to have been higher than that of CIs, probably close to 2 x CI, as suggested by the Sc abundances (Fig. 4). For the following calculations, we will assume concentrations $=1.8 \times \mathrm{CI}$ at the end of this step;

b/ first step of silicate melting, and formation of silica and alkali-rich melts; the proportions of the phases that melted during this step are uncertain; we used proportions similar to the ALM-A trachyandesite mode and assumed that these proportions were constant throughout this step. This stage would have terminated when plagioclase became exhausted. At the end of this step, we have assumed that the residual pyroxene would have been pigeonitic.

c/ second step of silicate melting, and melting of an ureilitic lithology; the residual lithology after the previous step contained mainly olivine and pigeonite. The highest temperatures attained by the ureilitic lithologies are not easy to estimate but were probably largely below $1400{ }^{\circ} \mathrm{C}$ based on melting experiments of harzburgites conducted at low pressure (e.g., Klingenberg and Kushiro, 1996).

In order to better characterize the differentiation process, we need a quantitative model of melting. Melt/residue partition coefficients can be calculated if the proportions of the phases in the residue are known. Several options are possible: batch or fractional, equilibrium or disequilibrium. When a restricted number of elements are considered, the various models can fit the data within uncertainties, provided that appropriate values for the unconstrained parameters are selected. However, when a large number of elements with different properties are selected, some of the models must be rejected, which is the major merit of modeling. This is illustrated below.

Fractionation models can be evaluated using REEs. However, they depend on many parameters (e.g., starting modal proportions in the ureilite precursors, melting proportions of the phases, partition coefficients) and assumptions, which are summarized in Tables 3 and 4. The mineralogical compositions of the chondritic precursors of the ureilites are among the most important parameters. Various models of partial melting of chondrites can be found in the literature, and usually invoke olivine-pyroxenes-plagioclase assemblages in agreement with the mineralogy of the least metamorphosed chondrites (type 3). However, the metamorphism of chondrites not only resulted in a coarsening of the textures but also led to the development of phosphate grains (merrillite and apatite), chiefly by oxidation of $\mathrm{P}$, which would initially have been contained by metal, as first suggested by Ahrens (1970). REEs migrated into phosphates during metamorphism (e.g., Murrell and Burnett, 1983), and these phases usually dominate the budget of these elements when present: REE abundances in chondritic phosphates are generally high, often on the order of $100 \mathrm{x}$ CI for merrillite (e.g., Jones et al., 2014). Therefore, the presence of phosphates during the melting of the ureilite precursors cannot be neglected and needs to be fully evaluated in order to derive a realistic differentiation model for the 
ureilites. In the following, we will consider three different assemblages with phases in chondritic proportions: one free of phosphate, an apatite-bearing source and a merrillite-bearing source. Because phosphates are easily melted, they certainly involved in during the formation of the silica and alkali-rich melts. We assume that they are totally consumed at the same time as plagioclase. The apatite partition coefficients we have used are those that were experimentally determined by Prowatke and Klemme (2006). Partition coefficients for merrillite are more uncertain, but are certainly much higher than those for apatite. We selected the apparent partition coefficients determined using a merrillite analysis obtained in a shergottite (Basu Sarbadhikari et al., 2009), that are consistent with the behavior of REEs in this phase (e.g., Jolliff et al., 1993). In addition, the Eu partition coefficients are generally dependent of the oxygen fugacity. During ureilite formation, $\mathrm{fO}_{2}$ was low (close to IW-2, and possibly lower, Goodrich et al., 2013b), and the behaviors of Eu and $\mathrm{Sr}$ were probably very similar. This is confirmed by the excellent correlation between $\mathrm{Eu} / \mathrm{Eu}^{*}$ and $\mathrm{Sr} / \mathrm{Eu} *$ ratios (Fig. 5). Consequently, the $\mathrm{Eu}$ and $\mathrm{Sr}$ partition coefficients are likely to have been similar during the melting of the ureilite precursors.

We initially assume that the melts were efficiently extracted from their sources, and consequently the melting processes would be analogous to fractional melting (Goodrich et al., 2007). The results of our calculations are shown in Figure 7. Using our set of parameters, plagioclase is exhausted and consequently no longer present in the residue after $16.5 \%$ of melting. The first important observation that emerges from our calculations is that the presence and the nature of the phosphate in the initial assemblage have a strong impact on the shapes of the REE patterns obtained for the residues. Fractional melting of a precursor devoid of phosphate (Fig. 7 at left), or containing apatite (Fig. 7 middle), cannot account for the REE abundances measured in ureilites. Thus, the REE pattern of the residue calculated at the end of the first step of silicate melting (red pattern "plagioclase out") crosses the ureilite fields, which is inconsistent with the lack of plagioclase in ureilites. On the other hand, fractional melting of a merrilite-bearing source produces residues with REE abundances that resemble group B ureilites. However, the calculated residues are much more lightREE depleted than the actual group A ureilites. A possible explanation for this discrepancy could be a disequilibrium partitioning limited by slow diffusion in pyroxenes during fractional melt extraction, as proposed by Goodrich et al. (2007, 2013). We have evaluated this possibility using the equations for disequilibrium fractional melting given by Liang and Liu (2016). We calculated the residues of melting for a range of disequilibrium parameter values $(\varepsilon)$ for the same three sources as above (phosphate free, apatite and merrilite-bearing). The results obtained for $\mathrm{F}$ (degree of melting experienced by the bulk solid) $=0.2$ are compared in Figure 8 with the compositions of the ureilites. Disequilibrium fractional melting can potentially explain the less-marked light REE depletions of the group A compared to the group B ureilites. However, it can only marginally account for the fine structure of the REE patterns. While this process cannot be firmly ruled out, other processes are possible, and we believe more likely. Thus, it is important to note that if a limited melt porosity developed during melting, then melting can no longer be considered to have been perfectly fractional. Dynamic melting is thus a more likely process (e.g., Zou, 1998). In Figure 8, we 
calculate the residues obtained by dynamic melting with a critical mass porosity $(\phi)$ of $2 \%$. Residues obtained with the merrilite-bearing sources display REE abundances similar to those of the group A ureilites (Fig. 9). From this we conclude that the dynamic melting of a merrillite-bearing source with $\phi$ ranging from 0 (fractional melting) to a couple of percent, can perfectly explain the REE abundances of both groups of ureilites (Figs. 6, 7 and 9). This model is consistent with $\mathrm{F}$ values ranging from 0.17 to 0.28 . We emphasize that these values are just indicative because they are model dependent. Calling for disequilibrium during partial melting is not necessary to explain the data, and in the absence of robust evidence looks more ad hoc than anything else.

Our new data and calculations have a number of important implications for the evolution of the ureilite parent body:

a) at least two types of magmas were generated by the partial melting of the UPB. When plagioclase was still present in the mantle, melts were probably aluminous; relics of these melts are rare and are at present limited to the feldspathic debris found in polymict ureilites and to the ALM-A lava (e.g., Ikeda et al., 2000; Cohen et al., 2004; Bischoff et al., 2014). It is likely that these magmas were alkali and silica rich. The segregation of these melts would have removed most of the aluminum in the UPB mantle, and consequently most of its ${ }^{26} \mathrm{Al}$, which is classically considered to provide the heat necessary for the melting of the small bodies. However, the exhaustion of ${ }^{26} \mathrm{Al}$ from the residues did not turn off magma formation; further melting of the residues after the exhaustion of plagioclase would necessarily have produced a different type of melt, certainly Al-poor and nearly alkali-free, which has not yet been identified. According to the model calculations, the average degree of melting of ureilites is between 0.2 and 0.25 , so that the mass of these $\mathrm{Al}$ and alkali-poor melts would have been about a third of that of the initial alkali and silica-rich magmas.

b) the bulk density at $1100^{\circ} \mathrm{C}$ of the ALM-A melt (calculated with the KWare Magma software) is 2.70 $\mathrm{g} / \mathrm{cm}^{3}$, and is lower than the average grain density of ureilites $\left(3.35 \mathrm{~g} / \mathrm{cm}^{3}\right)$ and carbonaceous chondrites (2.93 $\mathrm{g} / \mathrm{cm}^{3}$ for $\mathrm{C} 2$ chondrites, $3.6 \mathrm{~g} / \mathrm{cm}^{3}$ for C3-4 chondrites) determined by Macke et al. (2011a,b). Consequently, these lavas reached the surface of the body. If volcanism was explosive, part of these melts could have been lost to space (e.g., Warren and Kallemeyn, 1992). However, the feldspathic clasts found in polymict ureilites (e.g., Ikeda et al., 2000; Cohen et al., 2004) and the ALM-A trachyandesite (Bischoff et al., 2014) unambiguously indicate that at least some (if not all) of these volcanics were retained by the body. As a consequence, at least part of the melts generated during the first step of silicate melting could have formed a crust at the surface of the UPB. The density of the second type of magma was likely to have been higher than that of the initial feldspathic melts. At present we do not know the exact compositions of these second stage melts and so it is not possible to estimate their density contrast with their ureilitic residues. We speculate that these melts were unlikely to have reached the surface of the UPB, especially if a trachyandesitic crust covered the body. The possibility that these low-Al melts were slightly denser than 
ureilites, and could have formed an igneous layer below the ureilitic mantle requires further detailed evaluation.

c) the compositions of the olivine cores are not linked to the incompatible trace elements in ureilites (Fig. 10). Both smelting and gasless melting of ureilitic precursors can explain the data. If the ureilite precursors were $\mathrm{C}$-rich chondrites with rather homogeneous $\mathrm{Mg \#}$ numbers, smelting would be required to generate the range of olivine compositions. In that case, this process was particularly complex and independent of the behavior of incompatible elements. On the other hand, gasless melting of precursors with various Mg\# values is in perfect agreement with the decoupling between olivine core compositions and incompatible trace elements. It is noteworthy that ureilites with the highest $\mathrm{Mg \# s}$ and the highest temperatures of equilibrium estimated from pigeonite compositions using the method of Singletary and Grove (2003) belong to group B and display among the highest Sm abundances (Fig. 10) or Yb abundances (Fig. 4). Consequently they are among the least residual samples, which is rather astonishing should they be the most smelted samples. Moreover, the temperatures of equilibrium calculated with pigeonite compositions are probably not good estimates of partial melting conditions. They more likely mirror subsolidus reequilibration temperatures and cannot be used to discuss the partial melting history of the ureilites.

\section{Conclusions}

The incompatible trace element systematics of 17 ureilites confirms that they are mantle restites. They display a wide range of incompatible trace element abundances and ratios, and among them, striking light REE depletions, negative Eu anomalies, low $\mathrm{Zr} / \mathrm{Eu}^{*}$ and $\mathrm{Sr} / \mathrm{Eu}^{*}$ ratios which are strongly correlated. Our modelling of the REE abundances shows that:

a) the REE abundances of the residues from a chondritic precursor depend strongly on the presence of phosphates; this remark is important not only for ureilites, but should be taken into account to explain the REE distributions of other types of achondrites, especially the primitive ones. We suggest that the chondritic precursors of ureilites contained REE-rich phosphates, chiefly merrillite;

b) the REE abundances of the ureilites can be explained if at least two types of magmas were successively removed from their precursors. The first produced liquids consisted of aluminous melts whose existence is confirmed by feldspathic clasts known in polymict ureilites (e.g., Ikeda et al., 2000; Cohen et al., 2004) and by ALM-A, a trachyandesite found in the Almahata Sitta strewnfield (Bischoff et al., 2014). Partial melting continued after the exhaustion of plagioclase from the source, and REEs indicate that $\mathrm{Al}$ and alkali-poor melts were produced. Partial melting was near fractional to dynamic with melt porosities that did not exceed ca. a couple of percent.

Rocks formed from the low-Al, low-alkali magmas are totally unknown in the meteorite record, but our sampling of the UPB is far from being complete and representative. It would be interesting to 
determine the compositions of such melts. Experimental melting of ureilitic assemblages should now be undertaken to determine these compositions and to estimate the buoyancy of these melts within the UPB.

The successive eruptions of trachyandesitic lavas would almost certainly have built up a crust on the surface of the UPB. The formation of such magmas in a C-rich body casts doubts on the arguments of Weiss and Elkins-Tanton (2013) and Fu and Elkins-Tanton (2014) who suggested that magmas generated by partial melting of carbonaceous chondrites and possibly ordinary chondrites, were too dense to ascend to the surface of their parent bodies. However, this interpretation was obtained using previous experimental results. Subsequently, recent studies have shown that the melting of chondrites can generate at low $\mathrm{fO}_{2}$, silica and alkali enriched melts which are buoyant with respect to their precursors (Usui et al., 2015). Therefore, we suggest that the hypothesis of the preservation of a chondritic crust on some differentiated bodies needs a reappraisal. Clearly additional experimental work is required to explore the possible melting conditions and the diversity of magmas potentially generated by the various types of chondrites.

\section{Acknowledgements}

The ureilites from Antarctica were kindly provided by the Meteorite Working Group (NASA) and the National Institute of Polar Research, Tokyo. US Antarctic meteorite samples are recovered by the Antarctic search for Meteorites (ANSMET) program which has been funded by NSF and NASA, and characterized and curated in the Department of Mineral Sciences of the Smithsonian Institution and Astromaterials Curation Office at NASA Johnson Space Center. A dozen Saharan ureilites were generously provided by Bruno and Carine Fectay and Peter Marmet but the analyses were not integrated to this work because of their too-strong hot-desert flavors. The support of and discussions with Richard Greenwood are greatly acknowledged. We thank Christian Koeberl for the editorial handling, Hilary Downes and an anonymous reviewer for constructive comments, and Pascale Barrat for her help. This work was funded by grants from the Programme National de Planétologie (CNRS-INSU) to the first author. JAB dedicates this work to the memory of Guy Barrat, his father, who died in the spring of 2016.

\section{References}

Ahrens L.H. (1970) The composition of stony meteorites (VIII). Observations on fractionation between the L and the $\mathrm{H}$ chondrites. Earth Planet. Sci. Lett. 9, 345-347.

Barrat J.A., Keller F., Amossé J., Taylor R.N., Nesbitt R.W., Hirata T. (1996). Determination of rare earth elements in sixteen silicate reference samples by ICP-MS after Tm addition and ion exchange separation. Geostandards Newsletter 20, 1, 133-140.

Barrat J.A., Yamaguchi A., Zanda B., Bollinger C., Bohn M. (2010) Relative chronology of crust formation on asteroid 4-Vesta: Insights from the geochemistry of diogenites. Geochim. Cosmochim. Acta. 74, 6218-6231.

Barrat J.A., Zanda B., Moynier F., Bollinger C., Liorzou C., and Bayon G. (2012) Geochemistry of CI chondrites: Major and trace elements, and $\mathrm{Cu}$ and $\mathrm{Zn}$ isotopes. Geochim. Cosmochim. Acta 83, 79-92.

Barrat J.A., Zanda B., Jambon A., Bollinger C. (2014) The lithophile trace elements in enstatite chondrites. Geochim. Cosmochim. Acta. 128, 71-94.

Barrat J.A., Rouxel O., Wang K., Moynier F., Yamaguchi A., Bischoff A., Langlade J. (2015) Early stages of core segregation recorded by Fe isotopes: insights from the ureilite meteorites. Earth Planet. Sci. Lett. 419, 93-100. 
Barrat J.A., Dauphas N., Gillet P., Bollinger C., Etoubleau J., Bischoff A., Yamaguchi A. (2016) Evidence from Tm anomalies for non-CI refractory lithophile element proportions in terrestrial planets and achondrites. Geochim. Cosmochim. Acta, 176, 1-17.

Basu Sarbadhikari A, Day J.M.D., Liu Y., Rumble III D., Taylor L.A. (2009) Petrogenesis of olivine-phyric shergottite Larkman Nunatak 06319: Implications for enriched components in martian basalts. Geochim. Cosmochim. Acta 73, 2190-2214.

Bischoff A., Horstmann M., Barrat J.A., Chaussidon M., Pack A., Herwartz D., Ward D., Vollmer C., Decker S. (2014) trachyandesitic volcanism in the early Solar System. Proc. Natl. Acad. Sci. USA 111, 35, 12689-12692.

Boynton W.V., Starzyk P.M., and Schmitt R.A. (1976) Chemical evidence for the genesis of the ureilites, the achondrite Chassigny and the nakhlites. Geochim. Cosmochim. Acta 40, 1439-1447.

Budde G., Kruijer T.S., Fischer-Gödde M., Irving A.J., Kleine T. (2015) Planetesimal differentiation revealed by the Hf-W systematics of ureilites. Earth Planet. Sci. Lett. 430, 316-325.

Carporzen L., Weiss B.P., Elkins-Tanton L.T., Shuster D.L., Ebel D.S., Gattacceca J. (2011) Magnetic evidence for a partially differentiated carbonaceous chondrite parent body. Proc. Natl. Acad. Sci. USA 108, 6386-6389.

Clayton, R.N., Mayeda, T.K. (1996) Oxygen isotope studies of achondrites. Geochim. Cosmochim. Acta 69, 1999-2017.

Cohen, B.A., Goodrich, C.A., Keil, K. (2004) Feldspathic clast populations in polymict ureilites: Stalking the missing basalts from the ureilite parent body. Geochim. Cosmochim. Acta 68, 4249-4266.

Cournède C., Gattacceca J., Gounelle M., Rochette P., Weiss B.P., Zanda B. (2015) An early solar system magnetic field recorded in CM chondrites. Earth Planet. Sci. Lett. 410, 62-74.

Day J.M.D., Ash R.D., Liu Y., Bellucci J.J., Rumble D. III, McDonough W.F., Walker R.J., and Taylor L.A. (2009) Early formation of evolved asteroidal crust. Nature 457, 179-182.

Downes, H., Mittlefehldt, D.W., Kita, N.T., Valley, J.W. (2008) Evidence from polymict ureilite meteorites for a disrupted and reaccreted single ureilite parent asteroid gardened by several distinct impactors. Geochim Cosmochim Acta 72, 4825-4844.

Evans T.M., St. C. O’Neill H., Tuff J. (2008) The influence of melt composition on the partitioning of REEs, Y, Sc, Zr and Al between forsterite and melt in the system CMAS. Geochim. Cosmochim. Acta 72, 5708-5721.

Friedrich J.M., Wolf S., Rumble III D., Troiano J., Gagnon C.J.L., Compton J.R., Jenniskens P., Shaddad M.H. (2010) The elemental composition of Almahata Sitta. Meteoritics Planet. Sci. 45, 1718-1727.

Fu R.R., Elkins-Tanton L.T. (2014) The fate of magmas in planetesimals and the retention of primitive chondritic crusts. Earth Planet. Sci. Lett. 390, 128-138.

Gardner-Vandy K.G., McCoy T.J., Bullock E.S. (2014) Making evolved melts on asteroids. $\mathbf{4 5}^{\text {th }}$ Lunar Planet. Sci. Conf., \#1483 (abstract).

Goodrich C.A. (1992) Ureilites: A critical review. Meteoritics 27, 327-352.

Goodrich C.A., Wilson L. (2013) Non-basaltic magmatism on the ureilite parent body. Workshop on Planetesimal Formation and Differentiation, \# 8018 (abstract).

Goodrich C.A., Patchett P.J., Lugmair G.W., Drake M.J. (1991) Sm-Nd and Rb-Sr isotopic systematics of ureilites. Geochim. Cosmochim. Acta 55, 829-848.

Goodrich, C.A., Wlotzka, F., Ross, D. K. and Bartoschewitz, R. (2006) NWA 1500: plagioclase-bearing monomict ureilite or ungrouped achondrite? Meteorit. Planet. Sci. 41, 925-952 (2006).

Goodrich C.A., Van Orman J.A., Wilson L. (2007) Fractional melting and smelting on the ureilite parent body. Geochim. Cosmochim. Acta 71, 2876-2895.

Goodrich C.A., Hutcheon I.D., Kita N.T., Huss G.R., Cohen B.A., Keil, K. (2010) ${ }^{53} \mathrm{Mn}-{ }^{53} \mathrm{Cr}$ and ${ }^{26} \mathrm{Al}-{ }^{26} \mathrm{Mg}$ ages of a feldspathic lithology in polymict ureilites. Earth Planet. Sci. Lett. 295, 531-540. 
Goodrich C.A., Wilson L., van Orman J.A., Michel P. (2013) Comment on "Parent body depth-pressure-temperature relationships and the style of the ureilite anatexis" by P. H. Warren (MAPS 47:209-227) Meteoritics \& Planetary Science 48 1096-1106.

Goodrich C.A., Sutton S.R., Wirick S., Jercinovic M.J. (2013b) Chromium valences in ureilite olivine and implications for ureilite petrogenesis. Geochim. Cosmochim. Acta 122, 280-305.

Goodrich C.A., Hartmann W.K., O’Brien D., Weidenschilling S.J., Wilson L., Michel P., Jutzi M. (2015) Origin and history of ureilitic material in the solar system: the view from asteroid 2008 TC3 and the Almahata Sitti meteorite. Meteoritics Planet. Sci. 50, 782-809.

Greenwood, R.C., Franchi, I.A., Jambon, A., Buchanan, P. (2005) Widespread magma oceans on asteroidal bodies in the early solar system. Nature 435, 916-918.

Guan Y., Crozaz G. (2000) Light rare earth element enrichments in ureilites: a detailed ion microprobe study. Meteoritics Planet. Sci. 35, 131-144.

Ikeda Y., Prinz M., Nehru C.E. (2000) Lithic and mineral clasts in the Dar al Gani (DaG) 319 polymict ureilite. Antarctic Meteorite Research 13, 177-221.

Jolliff, B.L., Haskin, L.A. Colson, R.O., and Wadhwa, M. (1993) Partitioning in REE-saturating minerals: Theory, experiment, and modelling of whitlockite, apatite, and evolution of lunar residual magmas. Geochimica Cosmochimica Acta 57, 4069-4094.

Jones R.H., McCubbin F.M., Dreeland L., Guan Y., Burger P.V., Shearer C.K. (2014) Phosphate minerals in LL chondrites: A record of the action of fluids during metamorphism on ordinary chondrite parent bodies. Geochim. Cosmochim. Acta 132, 120-140.

Klingenberg B.M.E.T., Kushiro I. (1996) Melting of a chromite-bearing harzburgite and generation of boninitic melts at low pressures under controlled oxygen fugacity. Lithos 37, 1-13.

Liang Y, Liu B. (2016) Simple models for disequilibrium fractional melting and batch melting with application to REE fractionation in abyssal peridotites. Geochim. Cosmochim. Acta 173, 181-197.

Macke R.J., Britt D.T., Consolmagno G.J. (2011a) Density, porosity, and magnetic susceptibility of achondritic meteorites. Meteoritics Planet. Sci. 46, 311-326.

Macke R.J., Consolmagno G.J., Britt D.T. (2011b) Density, porosity, and magnetic susceptibility of carbonaceous chondrites. Meteoritics Planet. Sci. 46, 1842-1862.

McKay G., Le L. and Wagstaff J. (1991) Constraints on the origin of the mare basalt europium anomaly: REE partition coefficients for pigeonite. Lunar Planet. Sci. 22, 883-884.

Mittlefehldt D.W., McCoy T.J., Goodrich C.A., Kracher A. (1998) Non-chondritic me-teorites from asteroidal bodies. In: Papike, J.J. (Ed.), Planetary Materials. Mineralogical Society of America, Washington, DC, 195 pp.

Myiamoto M., Takeda H., Toyoda H. (1985) Cooling history of some Antarctic ureilites. J. Geophys. Res. 90 (supplement), D116D122.

Murrell M.T., Burnett D.S. (1983) The behavior of actinides, phosphorus, and rare earth elements during chondrite metamorphism. Geochim. Cosmochim Acta 47, 1999-2014

Prowatke S., Klemme S. (2006) Trace element partitioning between apatite and silicate melts. Geochim. Cosmochim. Acta 70, 45134527.

Rankenburg K., Humayun M., Brandon A. D., Herrin J.S. (2008) Highly siderophile elements in ureilites. Geochim. Cosmochim. Acta 72, 4642-4659.

Scott, E.R.D., Taylor, G.J., Keil, K. (1993) Origin of ureilite meteorites and implications for planetary accretion. Geophys. Res. Lett. 20, 415-418.

Severs M.J., Beard J.S., Fefele L., Hanchar J.M., Mutchler S.R., Bodnar R.J. (2009) Partitioning behavior of trace elements between dacitic melt and plagioclase, orthopyroxene, and clinopyroxene based on laser ablation ICPMS analysis of silicate melt inclusions. Geochim. Cosmochim. Acta 73, 2123-2141 
Shimizu H., Masuda A. (1981) REE, Ba, Sr and Rb abundances in some unique Antarctic achondrites. Memoirs of the National Institute of Polar Research, Tokyo, Special Issue n²0, 211-219.

Singletary, S. J. and Grove, T. L. (2003) Early petrologic processes on the ureilite parent body. Meteorit. Planet. Sci. 38, 95-108.

Spitz A.H., and Boynton W.V. (1991) Trace element analysis of ureilites: new constraints on their petrogenesis. Geochim. Cosmochim. Acta 55, 3417-3430.

Takeda H. (1987) Mineralogy of Antarctic ureilites and a working hypothesis for their origin and evolution. Earth Planet. Sci. Lett. 81, 358-370.

Usui T., Jones J.H., Mittlefehldt D.W. (2015) A partial melting study of an ordinary (H) chondrite composition with application to the unique achondrite Graves Nunataks 06128 and 06129. Meteoritics Planet. Sci. 50, 759-781.

Van Orman J.A., Grove T.L., Shimizu (2001) Rare earth element diffusion in diopside: influence of temperature, pressure and ionic radius, and an elastic model for diffusion in silicates. Contrib. Mineral. Petrol. 141, 687-703.

Wänke H., Baddenhausen H., Spettel B., Teschke F., Quijana-Rico M., Dreibus G., and Palme H. (1972) The chemistry of Haverö ureilite. Meteoritics 7, 579-590.

Warren P.H. (2011) Stable isotopes and the noncarbonaceous derivation of ureilites, in common with nearly all differentiated planetary materials. Geochim. Cosmochim. Acta 75, 6912-6926.

Warren P. H. (2012) Parent body depth-pressure-temperature relationships and the style of the ureilite anatexis. Meteoritics \& Planetary Science 47, 209-227.

Warren P. H. and Huber H. (2006) Ureilite petrogenesis: A limited role for smelting during anatexis and catastrophic disruption. Meteorit. Planet. Sci. 41, 835-849.

Warren P. H. and Kallemeyn G. W. (1992) Explosive volcanism and the graphite-oxygen fugacity buffer on the parent asteroid(s) of the ureilite meteorites. Icarus 100, 110-126.

Warren, P. H. and Rubin, A. E. (2010) Pyroxene-selective impact smelting in ureilites. Geochim. Cosmochim. Acta 74, 5109-5133.

Warren, P.H., Ulff-Moller, F., Huber, H., Kallemeyn, G.W. (2006) Siderophile geochemistry of ureilite: a record of early stages of planetesimal core formation. Geochim. Cosmochim. Acta 70, 2104-2126.

Weiss B.P., Elkins-Tanton L.T. (2013) Differentiated planetesimals and the parent bodies of chondrites. Annu. Rev. Earth Planet. Sci. 41, 529-560.

Wilson L., Goodrich C.A., van Orman J.A. (2008) Thermal evolution and physics of melt extraction on the ureilite parent body. Geochim. Cosmochim. Acta 72, 6154-6176.

Yamakawa A., Yamashita K., Makashima A. and Nakamura E. (2010) Chromium isotope systematics of achondrites: chronology and isotopic heterogeneity of the inner solar system. Astrophys. J. 720, 150-154.

Zou H. (1998) Trace element fractionation during modal and nonmodal dynamic melting and open-system melting: A mathematical treatment. Geochim. Cosmochim. Acta 62, 1937-1945. 
Table 1. Details of meteorite samples studied. Olivine compositions are from Downes et al. (2008) $)^{\mathrm{D}}$, Warren and Rubin (2010) ${ }^{\mathrm{WR}}$, and Barrat et al. (2015) .

\begin{tabular}{llccc}
\hline & source & mass & $\begin{array}{c}\text { olivine core } \\
\text { Fo\% }\end{array}$ & Remarks \\
Antarctica & & & & \\
A 881931,71 & NIPR & $0.5 \mathrm{~g}$ & $78.7^{\mathrm{B}}$ & \\
ALH 77257,105 & NIPR & $0.5 \mathrm{~g}$ & $86.1^{\mathrm{D}}$ & \\
ALH 81101,63 & MWG & $1.3 \mathrm{~g}$ & $78.9^{\mathrm{D}}$ & \\
ALH 82130,43 & MWG & $0.8 \mathrm{~g}$ & $95.2^{\mathrm{D}}$ & \\
EET 83225,37 & MWG & $0.8 \mathrm{~g}$ & $88.3^{\mathrm{D}}$ & \\
EET 96042,48 & MWG & $1.2 \mathrm{~g}$ & $81.3^{\mathrm{D}}$ & \\
GRA 95205,64 & MWG & $1.2 \mathrm{~g}$ & $79.2^{\mathrm{D}}$ & \\
GRO 95575,46 & MWG & $1.3 \mathrm{~g}$ & $78.6^{\mathrm{D}}$ & \\
LAP 03587,10 & MWG & $0.8 \mathrm{~g}$ & $74.7^{\mathrm{WR}}$ & \\
LAR 04315,46 & MWG & $0.8 \mathrm{~g}$ & $81.9^{\mathrm{WR}}$ & \\
MET 01085,23 & MWG & $0.7 \mathrm{~g}$ & no olivine & px Mg\#=88.8 \\
PCA 82506,125 & MWG & $1.4 \mathrm{~g}$ & $79.2^{\mathrm{D}}$ & \\
Y 790981,85 & NIPR & $0.6 \mathrm{~g}$ & $77.5^{\mathrm{D}}$ & \\
Y 791538,109 & NIPR & $0.5 \mathrm{~g}$ & $91.3^{\mathrm{D}}$ & \\
Y 981810,76 & NIPR & $0.5 \mathrm{~g}$ & $78.3^{\mathrm{B}}$ & \\
& & & & \\
Sahara & & & & \\
NWA 7686 & JAB & $1.8 \mathrm{~g}$ & $91.0^{\mathrm{B}}$ & \\
NWA 8049 & JAB & $2.0 \mathrm{~g}$ & $84.3^{\mathrm{B}}$ & \\
\hline
\end{tabular}


Table 2. Trace element abundances in unleached fractions $(U)$ and residues after leaching (R1, R2, R3, see the text for details) of ureilites.

\begin{tabular}{|c|c|c|c|c|c|c|c|c|c|c|c|c|c|c|c|c|c|c|c|c|}
\hline & & $A$ & A & ALH & ALH & ALH & ALH & ALH & ALH & EET & EET & EET & EET & GRA & GRA & GRO & GRO & GRO & LAP & LAP \\
\hline & & 881931 & 881931 & 77257 & 77257 & 81101 & 81101 & 82130 & 82130 & 83225 & 83225 & 96042 & 96042 & 95205 & 95205 & 95575 & 95575 & 95575 & 03587 & 03587 \\
\hline & & U & $\mathrm{R} 1$ & U & $\mathrm{R} 1$ & $U$ & $\mathrm{R} 1$ & $U$ & $\mathrm{R} 1$ & U & $\mathrm{R} 1$ & U & $\mathrm{R} 1$ & U & $\mathrm{R} 1$ & $U$ & R1a & $\mathrm{R} 1 \mathrm{~b}$ & U & $\mathrm{R} 1$ \\
\hline $\mathrm{CaO}$ & $w t \%$ & & 1.67 & & 0.91 & & 0.96 & & 2.62 & & 2.32 & & 1.42 & & 0.63 & & 1.56 & 1.47 & & 0.71 \\
\hline $\mathrm{Li}$ & $\mu \mathrm{g} / \mathrm{g}$ & 1.78 & 1.44 & 1.43 & 1.46 & 1.88 & 1.69 & 1.3 & 1.4 & 0.86 & 0.91 & 1.92 & 1.84 & 1.66 & 1.74 & 1.71 & 1.94 & 1.79 & 1.71 & 1.78 \\
\hline$P$ & $\mu \mathrm{g} / \mathrm{g}$ & 189 & 147 & 235 & 199 & 90 & 82 & 335 & 255 & 501 & 411 & 379 & 301 & 263 & 219 & 310 & 253 & 266 & 170 & 152 \\
\hline Sc & $\mu \mathrm{g} / \mathrm{g}$ & 9.08 & 10.25 & 7.06 & 7.13 & 7.42 & 6.83 & 11.32 & 12.63 & 13.83 & 14.03 & 8.68 & 8.78 & 6.67 & 6.79 & 8.61 & 9.37 & 9.04 & 7.32 & 7.77 \\
\hline $\mathrm{Ti}$ & $\mu \mathrm{g} / \mathrm{g}$ & 201 & 206 & 120 & 120 & 89.3 & 73.8 & 335 & 378 & 274 & 276 & 201 & 199 & 125 & 124 & 123 & 148 & 139 & 61.3 & 69.3 \\
\hline V & $\mu \mathrm{g} / \mathrm{g}$ & 97 & 91 & 91 & 92 & 86 & 82 & 116 & 113 & 106 & 112 & 96 & 96 & 82 & 84 & 96 & 103 & 101 & 88 & 89 \\
\hline $\mathrm{Cu}$ & $\mu \mathrm{g} / \mathrm{g}$ & 9.33 & 7.31 & 2.51 & 2.05 & 6.16 & 4.02 & 5.28 & 3.07 & 2.27 & 1.59 & 8.91 & 5.71 & 4.34 & 2.67 & 3.32 & 2.12 & 2.59 & 5.03 & 3.82 \\
\hline $\mathrm{Zn}$ & $\mu \mathrm{g} / \mathrm{g}$ & 240 & 198 & 204 & 212 & 114 & 110 & 180 & 193 & 99 & 107 & 221 & 220 & 154 & 146 & 130 & 139 & 133 & 238 & 233 \\
\hline $\mathrm{Ga}$ & $\mu \mathrm{g} / \mathrm{g}$ & 2.16 & 2.08 & 1.64 & 1.37 & 1.25 & 0.87 & 2.55 & 1.14 & 1.55 & 1.3 & 2.56 & 1.73 & 1.78 & 1.37 & 1.64 & 1.36 & 1.49 & 1.33 & 1.09 \\
\hline $\mathrm{Rb}$ & $\mathrm{ng} / \mathrm{g}$ & 96 & 85 & 3.1 & 4.9 & 7 & 6.4 & 12 & 14 & 5.3 & 1.8 & 38 & 42 & 40 & 42 & 7.4 & 5.9 & 12 & 17 & 8.8 \\
\hline $\mathrm{Sr}$ & $\mathrm{ng} / \mathrm{g}$ & 704 & 623 & 42 & 35 & 21 & 11 & 456 & 504 & 137 & 126 & 444 & 413 & 209 & 178 & 20 & 25 & 16 & 135 & 57 \\
\hline$Y$ & $\mathrm{ng} / \mathrm{g}$ & 465 & 465 & 152 & 151 & 106 & 102 & 755 & 859 & 670 & 677 & 383 & 404 & 209 & 212 & 104 & 113 & 112 & 98 & 102 \\
\hline $\mathrm{Zr}$ & $\mathrm{ng} / \mathrm{g}$ & 258 & 224 & 26 & 25 & 15 & 12 & 145 & 157 & 20 & 19 & 113 & 119 & 131 & 124 & 11 & 10 & 11 & 24 & 21 \\
\hline Cs & $\mathrm{ng} / \mathrm{g}$ & 8.04 & 5.71 & 1.35 & 0.6 & n.d. & 4.61 & 1.11 & 0.85 & 0.51 & 0.33 & 2.61 & 5.45 & 2.37 & 4.37 & 0.47 & n.d. & n.d. & 1.53 & 0.98 \\
\hline $\mathrm{Ba}$ & $\mathrm{ng} / \mathrm{g}$ & 233 & 187 & 8.51 & 4.67 & 6.66 & 2.46 & 32.4 & 20.9 & 38.0 & 14.2 & 55.9 & 54.1 & 59.6 & 55.3 & 4.9 & 2.2 & 10.1 & 43.7 & 23.8 \\
\hline La & $\mathrm{ng} / \mathrm{g}$ & 18.6 & 14.0 & 0.80 & 0.59 & 0.64 & 0.22 & 8.32 & 7.76 & 1.42 & 0.69 & 5.98 & 5.27 & 6.01 & 4.94 & 0.28 & 0.25 & 0.13 & 3.81 & 1.28 \\
\hline $\mathrm{Ce}$ & $\mathrm{ng} / \mathrm{g}$ & 46.8 & 35.2 & 3.47 & 1.88 & 1.78 & 0.74 & 31.2 & 31.1 & 5.13 & 3.13 & 18.1 & 16.2 & 15.6 & 13.3 & 1.12 & 0.68 & 0.40 & 8.63 & 3.18 \\
\hline $\operatorname{Pr}$ & $\mathrm{ng} / \mathrm{g}$ & 7.69 & 6.00 & 0.52 & 0.38 & 0.22 & 0.093 & 7.68 & 7.51 & 1.71 & 1.33 & 3.34 & 3.28 & 2.52 & 2.22 & 0.12 & 0.12 & 0.076 & 1.13 & 0.45 \\
\hline $\mathrm{Nd}$ & $\mathrm{ng} / \mathrm{g}$ & 42.9 & 34.9 & 3.22 & 2.72 & 1.03 & 0.674 & 54.2 & 60.8 & 19.9 & 18.0 & 23.0 & 22.5 & 14.0 & 12.8 & 0.76 & 0.78 & 0.63 & 5.24 & 2.63 \\
\hline $\mathrm{Sm}$ & $\mathrm{ng} / \mathrm{g}$ & 18.4 & 17.2 & 2.22 & 2.02 & 0.92 & 0.712 & 32.1 & 36.0 & 20.4 & 20.2 & 12.9 & 13.3 & 6.29 & 5.87 & 0.70 & 0.77 & 0.73 & 2.07 & 1.64 \\
\hline $\mathrm{Eu}$ & $\mathrm{ng} / \mathrm{g}$ & 5.29 & 4.67 & 0.56 & 0.337 & 0.137 & 0.118 & 3.81 & 4.39 & 1.76 & 1.60 & 3.04 & 3.10 & 1.85 & 1.67 & 0.169 & 0.176 & 0.157 & 0.44 & 0.49 \\
\hline $\mathrm{Gd}$ & $\mathrm{ng} / \mathrm{g}$ & 36.3 & 35.1 & 6.45 & 6.23 & 2.90 & 2.81 & 67.6 & 78.6 & 59.9 & 55.8 & 26.6 & 27.8 & 12 & 11.7 & 2.93 & 3.19 & 3.09 & 4.79 & 4.61 \\
\hline $\mathrm{Tb}$ & $\mathrm{ng} / \mathrm{g}$ & 8.51 & 8.31 & 1.95 & 1.85 & 0.97 & 0.959 & 15.2 & 17.4 & 13.8 & 13.1 & 6.3 & 6.47 & 2.92 & 2.84 & 0.95 & 1.08 & 1.06 & 1.21 & 1.31 \\
\hline Dy & $\mathrm{ng} / \mathrm{g}$ & 68.5 & 68.6 & 18.4 & 18.5 & 10.7 & 10.6 & 116 & 136 & 107 & 106 & 50.6 & 53 & 24.3 & 24.7 & 10.6 & 11.9 & 11.6 & 11.6 & 12.1 \\
\hline $\mathrm{Ho}$ & $\mathrm{ng} / \mathrm{g}$ & 18.3 & 18.2 & 5.79 & 5.64 & 3.46 & 3.43 & 28.8 & 34.6 & 27.3 & 27 & 13.1 & 13.8 & 6.81 & 6.85 & 3.38 & 3.87 & 3.74 & 3.41 & 3.57 \\
\hline Er & $\mathrm{ng} / \mathrm{g}$ & 61.9 & 61.9 & 22.5 & 22.6 & 15 & 14.3 & 96 & 111 & 89.5 & 85.2 & 44.8 & 47.5 & 25 & 25.3 & 14.6 & 16.2 & 15.9 & 13.7 & 14.1 \\
\hline $\mathrm{Yb}$ & $\mathrm{ng} / \mathrm{g}$ & 82.8 & 82.6 & 40.4 & 38.8 & 26.7 & 27.0 & 116 & 133 & 106 & 105 & 61.1 & 65.9 & 38.8 & 39.9 & 28.6 & 31.5 & 30.8 & 24.8 & 26.3 \\
\hline Lu & $\mathrm{ng} / \mathrm{g}$ & 14.4 & 14.0 & 7.52 & 7.20 & 5.37 & 5.36 & 18.9 & 21.5 & 17.7 & 16.6 & 10.9 & 11.5 & 7.16 & 7.31 & 5.91 & 6.37 & 6.15 & 4.99 & 5.26 \\
\hline$(\mathrm{La} / \mathrm{Sm})_{\mathrm{n}}$ & & 0.66 & 0.532 & 0.234 & 0.19 & 0.453 & 0.201 & 0.169 & 0.14 & 0.045 & 0.022 & 0.302 & 0.258 & 0.622 & 0.548 & 0.262 & 0.213 & 0.113 & 1.20 & 0.507 \\
\hline$(\operatorname{Pr} / \mathrm{Sm})_{\mathrm{n}}$ & & 0.702 & 0.587 & 0.391 & 0.317 & 0.397 & 0.22 & 0.402 & 0.35 & 0.141 & 0.111 & 0.436 & 0.415 & 0.675 & 0.637 & 0.298 & 0.255 & 0.175 & 0.919 & 0.458 \\
\hline
\end{tabular}




\begin{tabular}{|c|c|c|c|c|c|c|c|c|c|c|c|c|c|c|c|c|c|c|c|}
\hline$(\mathrm{Dy} / \mathrm{Lu})_{\mathrm{n}}$ & 0.46 & 0.475 & 0.237 & 0.249 & 0.192 & 0.191 & 0.597 & 0.612 & 0.586 & 0.619 & 0.45 & 0.446 & 0.328 & 0.327 & 0.173 & 0.181 & 0.183 & 0.225 & 0.223 \\
\hline $\mathrm{Eu} / \mathrm{Eu}^{*}$ & 0.619 & 0.576 & 0.446 & 0.288 & 0.253 & 0.254 & 0.248 & 0.250 & 0.152 & 0.144 & 0.497 & 0.489 & 0.643 & 0.611 & 0.357 & 0.339 & 0.316 & 0.428 & 0.540 \\
\hline$\left(\mathrm{Sr} / \mathrm{Eu}^{*}\right)_{\mathrm{n}}$ & 0.625 & 0.582 & 0.252 & 0.225 & 0.29 & 0.18 & 0.225 & 0.217 & 0.09 & 0.086 & 0.552 & 0.495 & 0.55 & 0.493 & 0.319 & 0.361 & 0.243 & 0.984 & 0.479 \\
\hline$\left(\mathrm{Zr} / \mathrm{Eu}^{*}\right)_{\mathrm{n}}$ & 0.504 & 0.460 & 0.348 & 0.359 & 0.466 & 0.442 & 0.157 & 0.148 & 0.028 & 0.029 & 0.308 & 0.314 & 0.76 & 0.754 & 0.381 & 0.330 & 0.370 & 0.386 & 0.392 \\
\hline
\end{tabular}

Table 2 (continue)

\begin{tabular}{|c|c|c|c|c|c|c|c|c|c|c|c|c|c|c|c|c|c|c|}
\hline & & LAR & LAR & MET & MET & PCA & PCA & $\mathrm{Y}$ & $Y$ & $\mathrm{Y}$ & $\mathrm{Y}$ & $\mathrm{Y}$ & $\mathrm{Y}$ & NWA & NWA & NWA & NWA & NWA \\
\hline & & 04315 & 04315 & 01085 & 01085 & 82506 & 82506 & 790981 & 790981 & 791538 & 791538 & 981810 & 981810 & 7686 & 7686 & 8049 & 8049 & 8049 \\
\hline & & $U$ & $\mathrm{R} 1$ & $U$ & R3 & $U$ & R1 & $U$ & R1 & $U$ & R1 & U & $\mathrm{R} 1$ & U & $\mathrm{R} 1$ & $U$ & R1 & $\mathrm{R} 2$ \\
\hline $\mathrm{CaO}$ & wt\% & & 1.69 & & 2.23 & & 1.16 & & 1.09 & & 1.65 & & 0.98 & & 1.39 & & 1.16 & 1.12 \\
\hline $\mathrm{Li}$ & $\mu \mathrm{g} / \mathrm{g}$ & 1.66 & 1.55 & 0.69 & 0.69 & 1.54 & 1.61 & 1.8 & 1.71 & 1.46 & 1.52 & 1.57 & 1.67 & 1.49 & 1.53 & 1.41 & 1.48 & 1.53 \\
\hline$P$ & $\mu \mathrm{g} / \mathrm{g}$ & 257 & 255 & 506 & 182 & 270 & 220 & 337 & 284 & 546 & 401 & 276 & 223 & 526 & 474 & 261 & 230 & 233 \\
\hline $\mathrm{Sc}$ & $\mu \mathrm{g} / \mathrm{g}$ & 8.82 & 10.04 & 16.66 & 17.35 & 8.24 & 8.89 & 7.49 & 7.9 & 10.2 & 10.49 & 8.4 & 7.76 & 8.41 & 9.27 & 7.69 & 8.06 & 8.67 \\
\hline $\mathrm{Ti}$ & $\mu \mathrm{g} / \mathrm{g}$ & 167 & 199 & 556 & 590 & 141 & 154 & 163 & 161 & 297 & 298 & 138 & 119 & 204 & 224 & 112 & 117 & 126 \\
\hline V & $\mu \mathrm{g} / \mathrm{g}$ & 89 & 94 & 110 & 117 & 99 & 103 & 85 & 80 & 91 & 92 & 85 & 84 & 88 & 92 & 87 & 92 & 95 \\
\hline $\mathrm{Cu}$ & $\mu \mathrm{g} / \mathrm{g}$ & 7.33 & 5.65 & 5.18 & 1.96 & 3.29 & 2.29 & 12.55 & 9.71 & 3.82 & 2.93 & 11.38 & 9.13 & 5.54 & 3.76 & 4.2 & 1.82 & 1.51 \\
\hline $\mathrm{Zn}$ & $\mu \mathrm{g} / \mathrm{g}$ & 161 & 152 & 89 & 96 & 170 & 174 & 252 & 232 & 228 & 237 & 227 & 245 & 236 & 235 & 199 & 215 & 229 \\
\hline $\mathrm{Ga}$ & $\mu \mathrm{g} / \mathrm{g}$ & 1.96 & 1.31 & 2.95 & 2.43 & 2.02 & 1.72 & 2.39 & 2.06 & 2.51 & 1.76 & 1.72 & 1.23 & 2.47 & 2.12 & 1.57 & 1.34 & 1.39 \\
\hline $\mathrm{Rb}$ & $\mathrm{ng} / \mathrm{g}$ & 7.7 & 5.1 & 14 & 13 & 15 & 13 & 117 & 108 & 12 & 12 & 82 & 75 & 6.1 & 6.4 & 12 & 7.6 & 7.1 \\
\hline $\mathrm{Sr}$ & $\mathrm{ng} / \mathrm{g}$ & 121 & 113 & 645 & 525 & 65 & 59 & 785 & 727 & 148 & 144 & 519 & 396 & 224 & 235 & 132 & 177 & 172 \\
\hline$Y$ & $\mathrm{ng} / \mathrm{g}$ & 298 & 345 & 1181 & 1188 & 164 & 172 & 425 & 424 & 542 & 534 & 293 & 248 & 375 & 420 & 167 & 165 & 169 \\
\hline $\mathrm{Zr}$ & $\mathrm{ng} / \mathrm{g}$ & 52 & 50 & 264 & 242 & 22 & 24 & 339 & 332 & 24 & 30 & 196 & 176 & 24 & 17 & 28 & 25 & 22 \\
\hline $\mathrm{Ba}$ & $\mathrm{ng} / \mathrm{g}$ & 5.64 & 7.69 & 113 & 39.7 & 9.66 & 7.34 & 295 & 233 & 19.7 & 14.3 & 201 & 124 & 13 & 10 & 392 & 80 & 83 \\
\hline $\mathrm{La}$ & $\mathrm{ng} / \mathrm{g}$ & 2.41 & 1.63 & 9.33 & 5.76 & 0.72 & 0.66 & 22.6 & 19.5 & 1.35 & 1.08 & 18.6 & 11.7 & 0.88 & 0.86 & 1.79 & 1.42 & 1.18 \\
\hline $\mathrm{Ce}$ & $\mathrm{ng} / \mathrm{g}$ & 7.45 & 6.25 & 31.6 & 22.1 & 3.17 & 2.1 & 55.3 & 48.9 & 5.72 & 4.09 & 47.1 & 30.8 & 4.26 & 3.85 & 4.9 & 3.99 & 3.49 \\
\hline $\mathrm{Pr}$ & $\mathrm{ng} / \mathrm{g}$ & 1.89 & 1.71 & 7.21 & 5.24 & 0.49 & 0.42 & 9.11 & 8.14 & 1.36 & 1.1 & 7.4 & 5.1 & 1.11 & 1.18 & 0.84 & 0.68 & 0.63 \\
\hline $\mathrm{Nd}$ & $\mathrm{ng} / \mathrm{g}$ & 14.6 & 15.8 & 52.6 & 44.5 & 2.98 & 2.95 & 49.2 & 46.3 & 11.3 & 10.8 & 37.9 & 28.6 & 10.7 & 12.1 & 4.65 & 4.21 & 3.96 \\
\hline $\mathrm{Sm}$ & $\mathrm{ng} / \mathrm{g}$ & 10.7 & 11.9 & 35.3 & 31.7 & 2.04 & 2.18 & 20.4 & 20.6 & 10.9 & 11.1 & 14.4 & 11.7 & 9.13 & 11.0 & 2.88 & 2.70 & 2.67 \\
\hline $\mathrm{Eu}$ & $\mathrm{ng} / \mathrm{g}$ & 1.21 & 1.31 & 6.45 & 5.23 & 0.56 & 0.592 & 6.39 & 6.27 & 1.53 & 1.40 & 4.05 & 3.30 & 1.94 & 2.11 & 0.52 & 0.644 & 0.603 \\
\hline $\mathrm{Gd}$ & $\mathrm{ng} / \mathrm{g}$ & 23.6 & 28.3 & 85.8 & 80.6 & 6.00 & 6.36 & 35.9 & 37.7 & 32.3 & 32.6 & 25.2 & 20.2 & 23.2 & 28.7 & 7.23 & 7.24 & 7.63 \\
\hline $\mathrm{Tb}$ & $\mathrm{ng} / \mathrm{g}$ & 5.35 & 6.68 & 20.8 & 20.5 & 1.79 & 1.90 & 8.01 & 8.3 & 8.73 & 8.76 & 5.48 & 4.43 & 6.01 & 7.23 & 2.35 & 2.06 & 2.14 \\
\hline
\end{tabular}




\begin{tabular}{|c|c|c|c|c|c|c|c|c|c|c|c|c|c|c|c|c|c|c|}
\hline Dy & $\mathrm{ng} / \mathrm{g}$ & 45.0 & 53.8 & 172 & 174 & 18.1 & 19.0 & 64.5 & 66.0 & 79.5 & 77.9 & 42.5 & 35.5 & 52.1 & 63.3 & 21.5 & 20.2 & 20.5 \\
\hline Ho & $\mathrm{ng} / \mathrm{g}$ & 11.6 & 14.1 & 44.6 & 46.3 & 5.48 & 5.81 & 15.9 & 16.8 & 21.3 & 21.4 & 11.0 & 9.19 & 14.6 & 17.3 & 6.37 & 6.04 & 6.18 \\
\hline $\mathrm{Er}$ & $\mathrm{ng} / \mathrm{g}$ & 40.4 & 47.1 & 159 & 159 & 21.7 & 23.1 & 54.7 & 56.4 & 74.4 & 75.3 & 38 & 32.2 & 50.6 & 60.8 & 24.7 & 23.6 & 23.8 \\
\hline $\mathrm{Yb}$ & $\mathrm{ng} / \mathrm{g}$ & 60.4 & 64.5 & 206 & 204 & 37.1 & 39.4 & 70.2 & 73.4 & 102 & 102 & 52.7 & 47.3 & 72.1 & 82.7 & 43.5 & 40.6 & 40.8 \\
\hline Lu & $\mathrm{ng} / \mathrm{g}$ & 11.4 & 11.1 & 34.1 & 33.1 & 7.17 & 7.43 & 11.8 & 12.5 & 17.4 & 17.3 & 9.65 & 8.60 & 13.1 & 14.1 & 8.30 & 7.62 & 7.68 \\
\hline$(\mathrm{La} / \mathrm{Sm})_{\mathrm{n}}$ & & 0.147 & 0.089 & 0.172 & 0.118 & 0.230 & 0.197 & 0.723 & 0.616 & 0.081 & 0.063 & 0.838 & 0.65 & 0.062 & 0.051 & 0.405 & 0.344 & 0.288 \\
\hline$(\mathrm{Pr} / \mathrm{Sm})_{\mathrm{n}}$ & & 0.297 & 0.243 & 0.343 & 0.278 & 0.401 & 0.324 & 0.752 & 0.663 & 0.209 & 0.167 & 0.863 & 0.732 & 0.204 & 0.182 & 0.489 & 0.427 & 0.395 \\
\hline$(D y / L u)_{n}$ & & 0.382 & 0.471 & 0.489 & 0.51 & 0.244 & 0.248 & 0.532 & 0.512 & 0.442 & 0.436 & 0.427 & 0.399 & 0.386 & 0.434 & 0.25 & 0.257 & 0.258 \\
\hline $\mathrm{Eu} / \mathrm{Eu}^{*}$ & & 0.231 & 0.217 & 0.355 & 0.314 & 0.484 & 0.482 & 0.716 & 0.681 & 0.246 & 0.224 & 0.644 & 0.65 & 0.404 & 0.361 & 0.345 & 0.441 & 0.404 \\
\hline$\left(\mathrm{Sr} / \mathrm{Eu}^{*}\right)_{\mathrm{n}}$ & & 0.175 & 0.142 & 0.269 & 0.239 & 0.424 & 0.362 & 0.667 & 0.599 & 0.181 & 0.174 & 0.626 & 0.592 & 0.354 & 0.305 & 0.664 & 0.918 & 0.873 \\
\hline$\left(\mathrm{Zr} / \mathrm{Eu}^{*}\right)_{\mathrm{n}}$ & & 0.167 & 0.137 & 0.242 & 0.242 & 0.323 & 0.331 & 0.632 & 0.601 & 0.064 & 0.080 & 0.519 & 0.576 & 0.082 & 0.049 & 0.304 & 0.282 & 0.244 \\
\hline
\end{tabular}


Table 3. Starting modal compositions, and melting proportions (melting step, 1: with plagioclase; 2: after plagioclase exhaustion).

\begin{tabular}{|c|c|c|c|c|c|c|c|}
\hline & olivine & orthopyroxene & clinopyroxene & pigeonite & plagioclase & apatite & merrillite \\
\hline \multicolumn{8}{|l|}{ starting compositions, step 1} \\
\hline phosphate-free source & 53 & 31 & 5 & 0 & 11 & 0 & 0 \\
\hline apatite-bearing source & 52.7 & 31 & 5 & 0 & 11 & 0.3 & 0 \\
\hline merrillite-bearing source & 52.7 & 31 & 5 & 0 & 11 & 0 & 0.3 \\
\hline \multicolumn{8}{|l|}{ melting proportions, step 1} \\
\hline phosphate-free source & & 13.9 & 19.4 & & 66.7 & & \\
\hline apatite-bearing source & & 12.1 & 19.4 & & 66.7 & 1.82 & \\
\hline merrillite-bearing source & & 12.1 & 19.4 & & 66.7 & & 1.82 \\
\hline melting proportions, step 2 & 50 & & & 50 & & & \\
\hline
\end{tabular}


Table 4. Mineral-melt partition coefficients and desequilibrium parameter used for calculations (melting step, 1: with plagioclase; 2: after plagioclase exhaustion). For each phase, the REE partition coefficients (except Eu) were recalculated using the best-fit order-3 polynome in a Log D vs. ionic radius plot from literature data (a : Evans et al., 2008 ; b : Severs et al., 2009 ; c : Prowatke and Klemme, 2006 ; d : Basu Sarbadhikari et al., 2009 ; e : McKay et al., 1991). The Eu and $\mathrm{Sr}$ partition coefficients were assumed to be similar during ureilite melting. This assumption is justified by the strong correlation between $\mathrm{Eu} / \mathrm{Eu}^{*}$ and $\mathrm{Sr} / \mathrm{Eu} *$ (Fig. 5). The disequilibrium parameters for REE $\left(\varepsilon_{\mathrm{REE}}\right)$ are deduced from their diffusion parameters in diopside at $1200^{\circ} \mathrm{C}(\mathrm{Van}$ Orman et al., 2001), with $\varepsilon_{\text {La }}$ fixed at 1 .

\begin{tabular}{lcccccccc}
\hline & olivine & orthopyroxene & clinopyroxene & plagioclase & apatite & merrillite & pigeonite & $\mathcal{E}_{\text {REE }}$ \\
reference & $\mathrm{a}$ & $\mathrm{b}$ & $\mathrm{b}$ & $\mathrm{b}$ & $\mathrm{c}$ & $\mathrm{d}$ & $\mathrm{e}$ & \\
melting step & 1,2 & 1 & 1 & 1 & 1 & 1 & 2 & 1,2 \\
& & & & & & & & \\
$\mathrm{Sr}$ & $4.60 \mathrm{E}-05$ & 0.003 & 0.101 & 2.42 & 4.3 & 2.73 & 0.002 & \\
$\mathrm{La}$ & $4.87 \mathrm{E}-06$ & 0.003 & 0.082 & 0.087 & 10.99 & 68.6 & 0.0008 & 1.00 \\
$\mathrm{Ce}$ & $1.23 \mathrm{E}-05$ & 0.0051 & 0.15 & 0.079 & 13.36 & 75.1 & 0.0017 & 0.914 \\
$\mathrm{Pr}$ & $3.00 \mathrm{E}-05$ & 0.0088 & 0.249 & 0.068 & 15.15 & 79.4 & 0.0033 & 0.772 \\
$\mathrm{Nd}$ & $7.04 \mathrm{E}-05$ & 0.0148 & 0.376 & 0.057 & 16.06 & 81.3 & 0.0056 & 0.609 \\
$\mathrm{Sm}$ & $2.94 \mathrm{E}-04$ & 0.0355 & 0.635 & 0.037 & 15.29 & 79.2 & 0.0118 & 0.349 \\
$\mathrm{Eu}$ & $=\mathrm{D}$ & $=\mathrm{D} \mathrm{Sr}$ & $=\mathrm{D}$ Sr & $=\mathrm{D}_{\mathrm{Sr}}$ & $=\mathrm{D}$ Sr & $=\mathrm{D}$ Sr & 0.005 & 0.262 \\
$\mathrm{Gd}$ & $9.56 \mathrm{E}-04$ & 0.0724 & 0.835 & 0.025 & 12.67 & 73.1 & 0.0203 & 0.193 \\
$\mathrm{~Tb}$ & 0.0017 & 0.101 & 0.908 & 0.02 & 11.02 & 69.2 & 0.0262 & 0.140 \\
$\mathrm{Dy}$ & 0.00298 & 0.14 & 0.957 & 0.017 & 9.3 & 64.9 & 0.0338 & 0.101 \\
$\mathrm{Ho}$ & 0.00499 & 0.186 & 0.981 & 0.014 & 7.77 & 60.7 & 0.0433 & 0.0736 \\
$\mathrm{Er}$ & 0.00798 & 0.238 & 0.986 & 0.012 & 6.46 & 57.0 & 0.0550 & 0.0551 \\
$\mathrm{Tm}$ & 0.0122 & 0.295 & 0.978 & 0.011 & 5.38 & 53.6 & 0.0695 & 0.0424 \\
$\mathrm{Yb}$ & 0.0179 & 0.354 & 0.962 & 0.010 & 4.51 & 50.6 & 0.0873 & 0.0336 \\
$\mathrm{Lu}$ & 0.0251 & 0.414 & 0.942 & 0.009 & 3.82 & 48.1 & 0.109 & 0.0274 \\
\hline
\end{tabular}



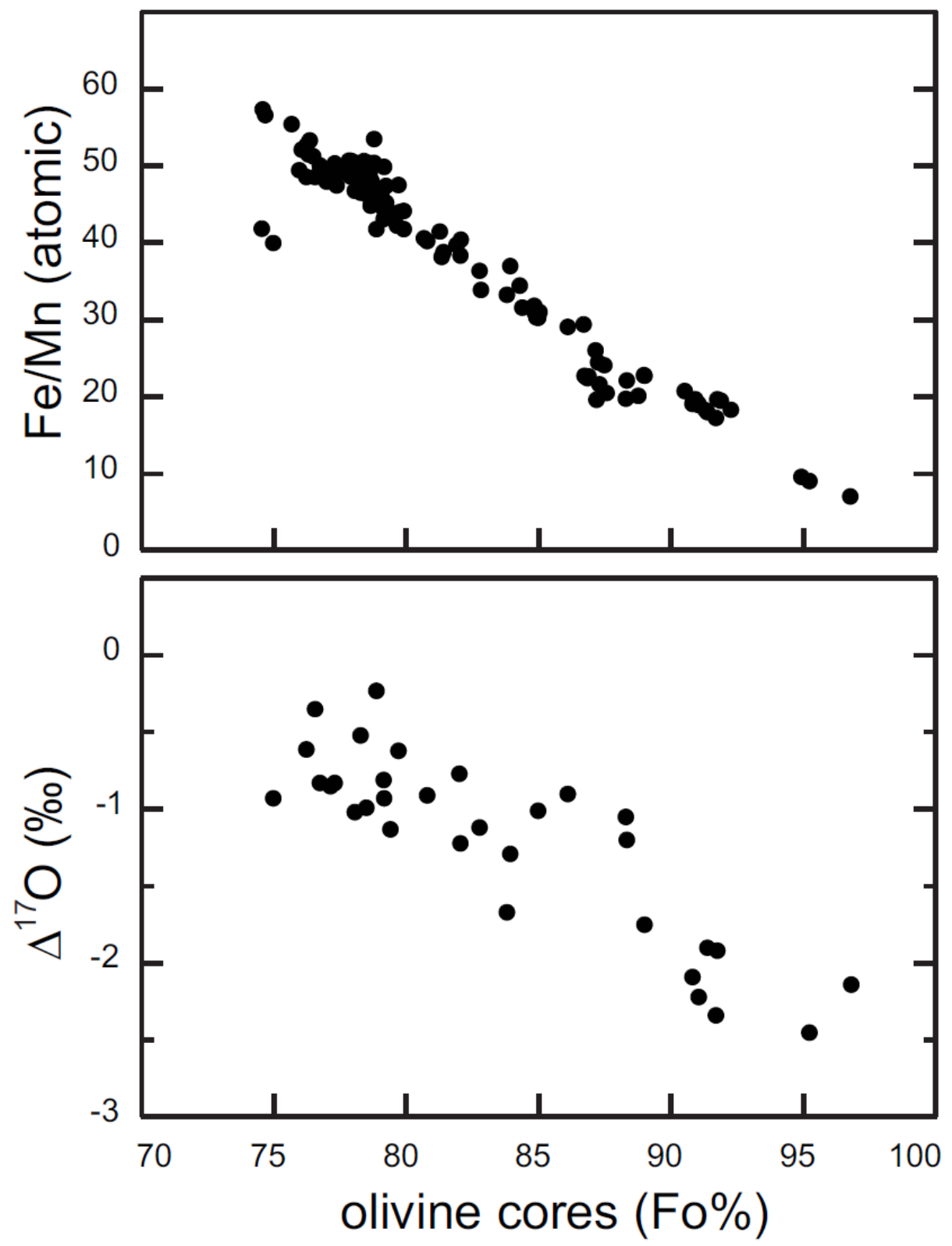

Figure 1. Plots of molar Fe/Mn ratios in olivine cores and $\Delta^{17} \mathrm{O}$ (Clayton and Mayeda, 1996) vs. the composition of the olivine cores (data mainly from Downes et al., 2008, Singletary and Grove, 2003, Goodrich et al., 2006; Barrat et al., 2015 and references therein). 

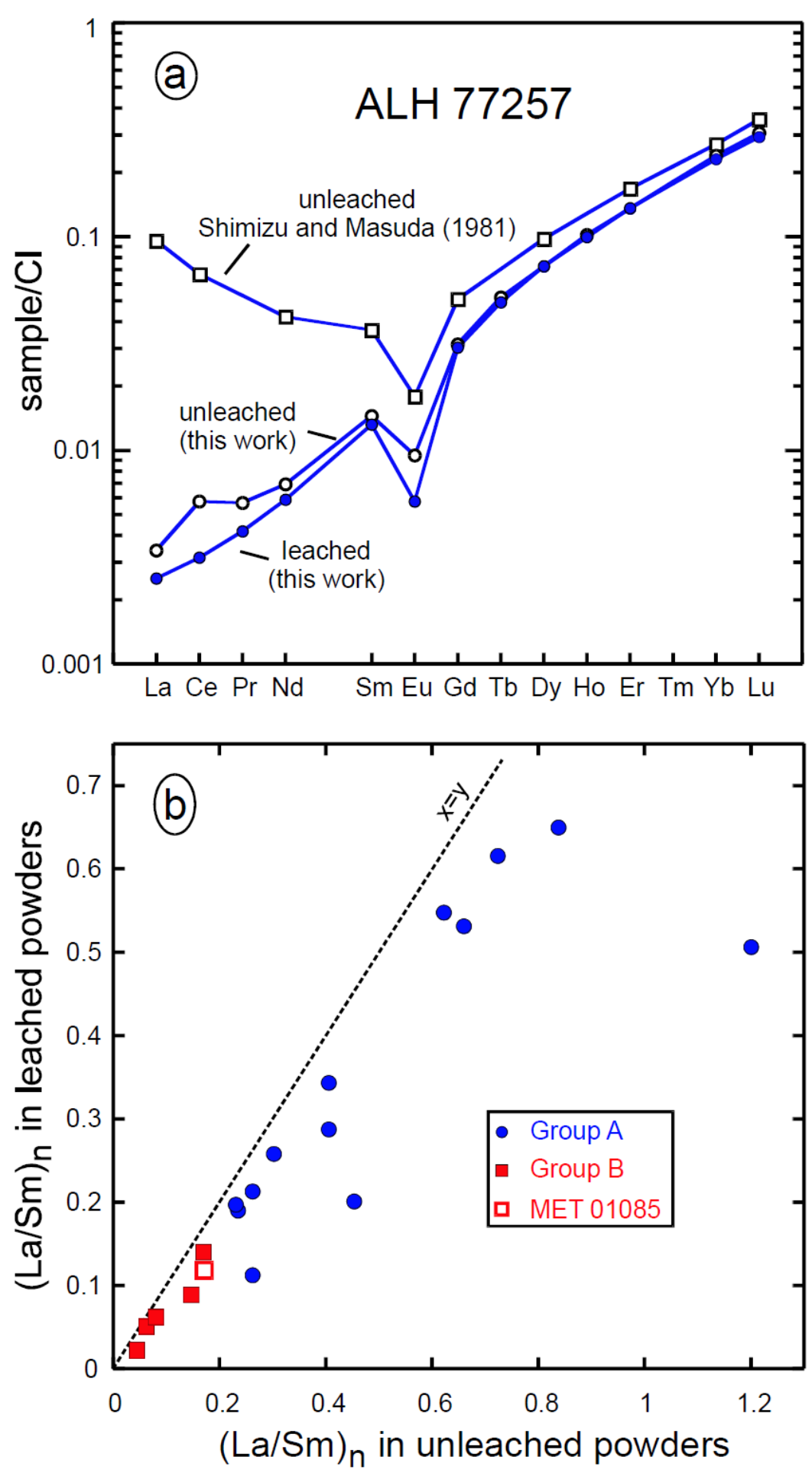

Figure 2. a) Selected REE patterns obtained for ALH 77257 normalized to CI chondrite (Barrat et al., 2012). Results obtained with unleached fractions display the fingerprints of a secondary component (positive Ce anomaly, light REE enrichment). These features are removed after leaching. Notice that the results obtained after leaching display the same Sm and heavy-REE abundances as the unleached powder (this work), and indicate that the residue is not pyroxene-enriched (no effect of selective dissolution of olivine). b) $(\mathrm{La} / \mathrm{Sm})_{\mathrm{n}}$ ratios in the residues compared to the same ratios in the unleached powders. The residues display lower $(\mathrm{La} / \mathrm{Sm})_{\mathrm{n}}$ ratios than the unleached powders, demonstrating that light-REE enriched secondary components were removed by the leaching step for all the samples. 


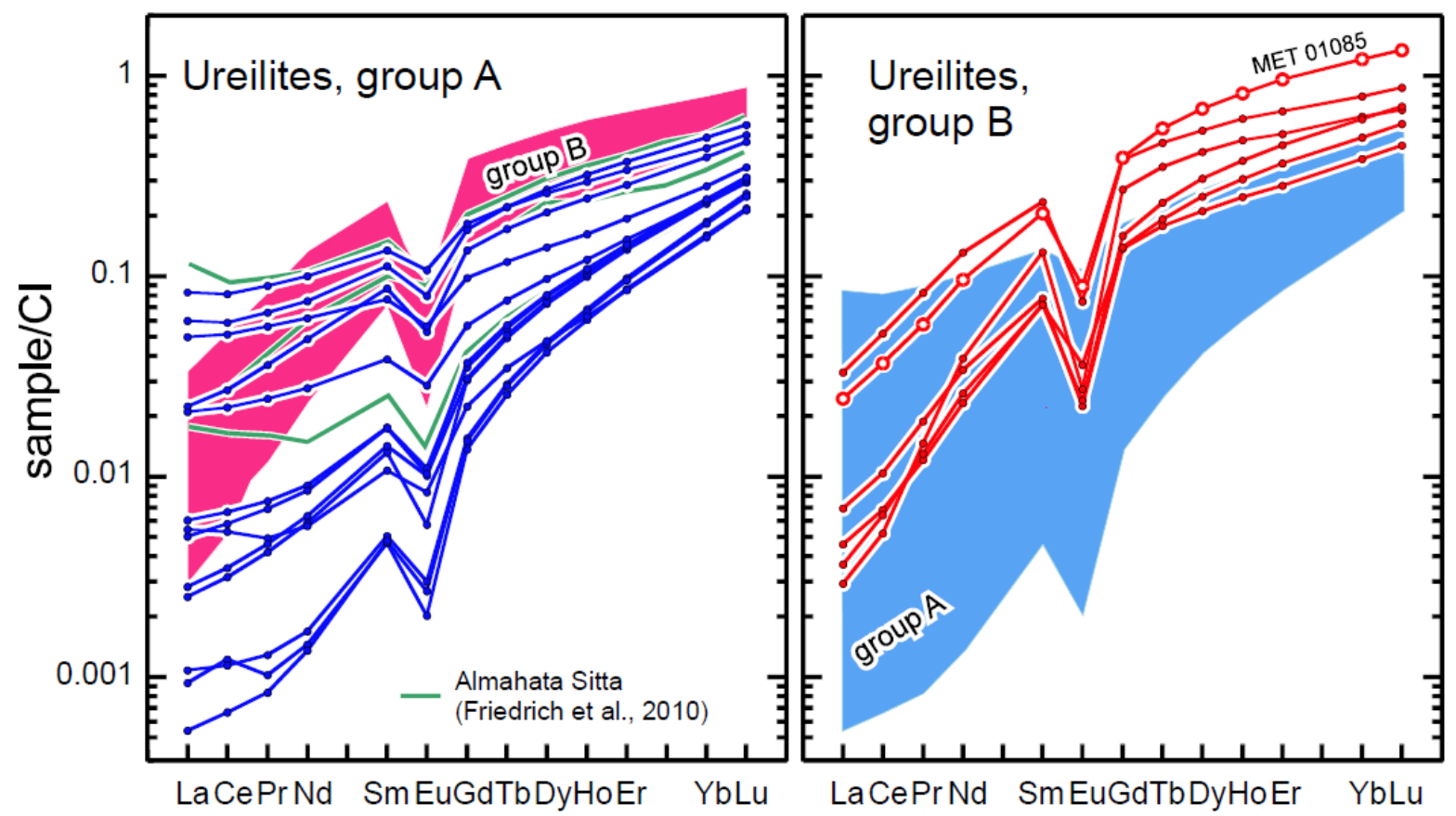

Figure 3. REE patterns of ureilites (leached samples), normalized to CI chondrite (Barrat et al., 2012). The patterns of three Almahata Sitta ureilites are shown for comparison (Friedrich et al., 2010). 


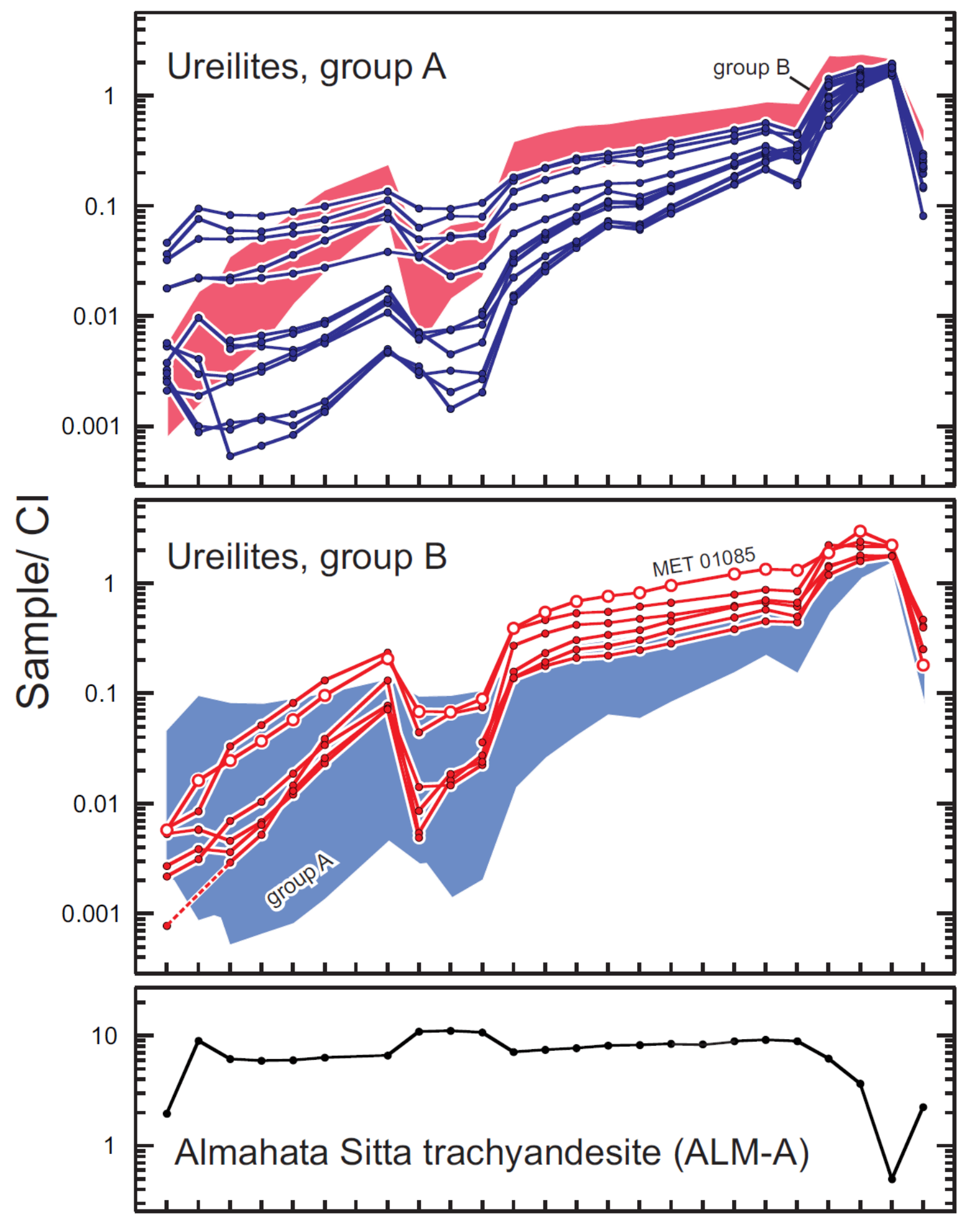

RbBaLaCe PrNd SmZr SrEuGdTbDy Y HoErTmYbLu Ti CaSc V P

Figure 4. Trace element patterns of ureilites (concentrations obtained with the leached samples, except for $\mathrm{P}$ for which the concentrations in the unleached fractions were selected) and for the ALM-A trachyandesite (Bischoff et al., 2014) normalized to CI chondrite (Barrat et al., 2012). Ba and Sr abundances in the two Saharan samples have been omitted. 


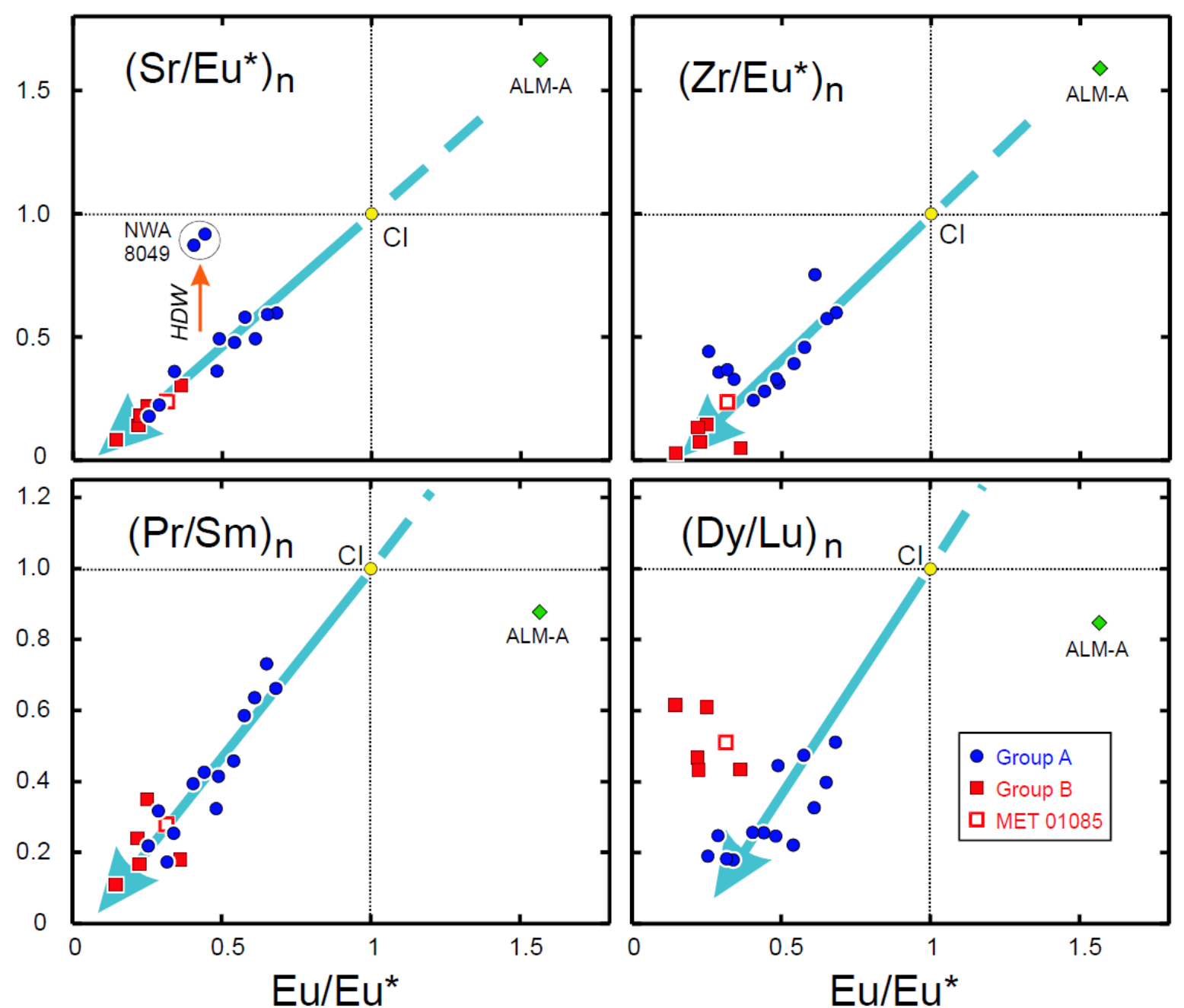

Figure 5. $(\mathrm{Sr} / \mathrm{Eu})_{\mathrm{n}},(\mathrm{Zr} / \mathrm{Eu})_{\mathrm{n}},(\mathrm{Pr} / \mathrm{Sm})_{\mathrm{n}},(\mathrm{Dy} / \mathrm{Lu})_{\mathrm{n}} \mathrm{vs} . \mathrm{Eu} / \mathrm{Eu}^{*}$ plots for ureilites (leached samples). Hot desert weathering (HDW) is responsible of the high $\mathrm{Sr} / \mathrm{Eu}^{*}$ ratios displayed by NWA 8049. 

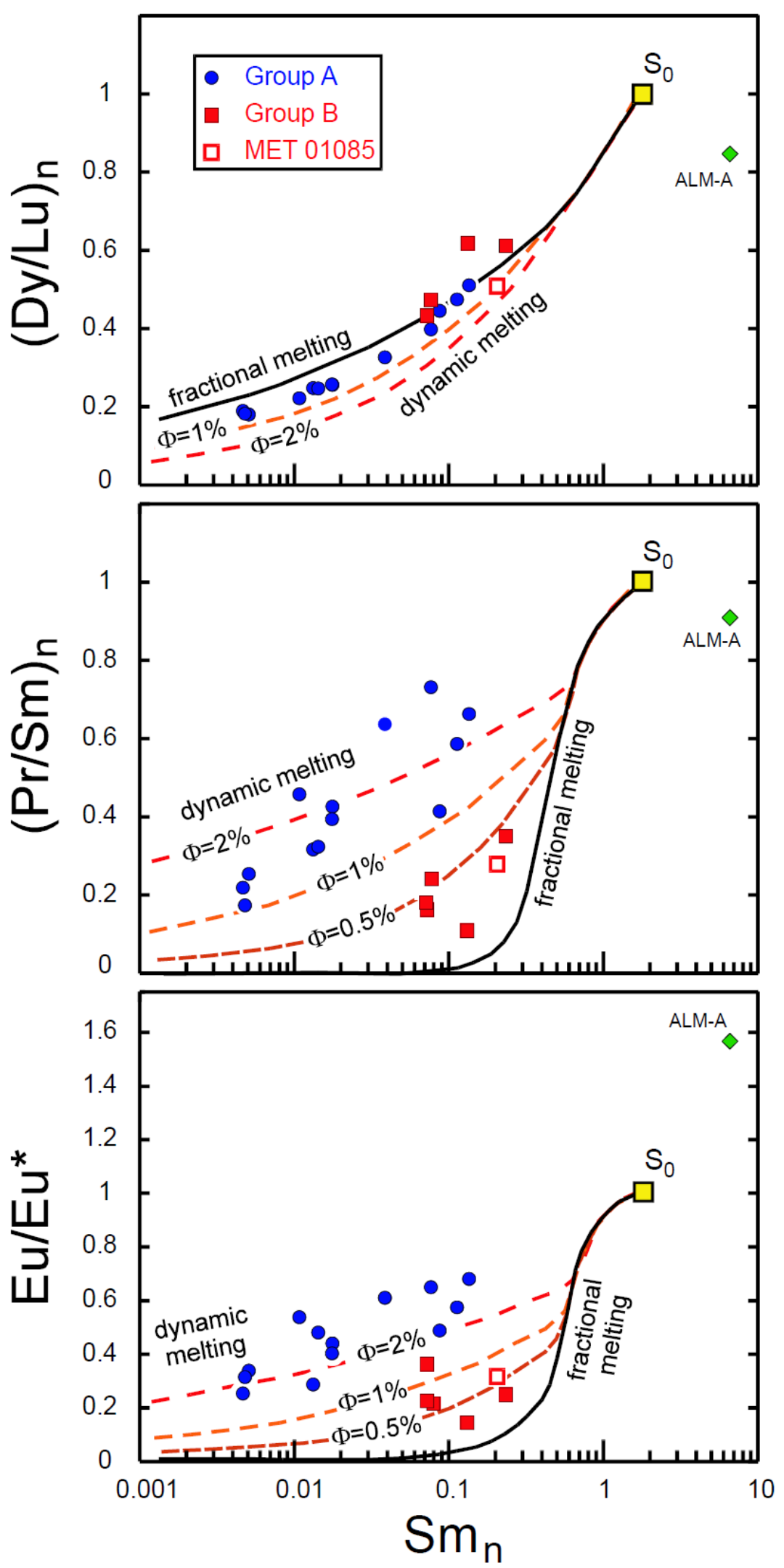

Figure 6. $(\mathrm{Dy} / \mathrm{Lu})_{\mathrm{n}},(\mathrm{Pr} / \mathrm{Sm})_{\mathrm{n}}$, and $\mathrm{Eu} / \mathrm{Eu}^{*}$ vs. $\mathrm{Sm}_{\mathrm{n}}$ plots for ureilites (leached samples). The partial melting curves obtained for a merrillite-bearing assemblage are shown for comparison. 


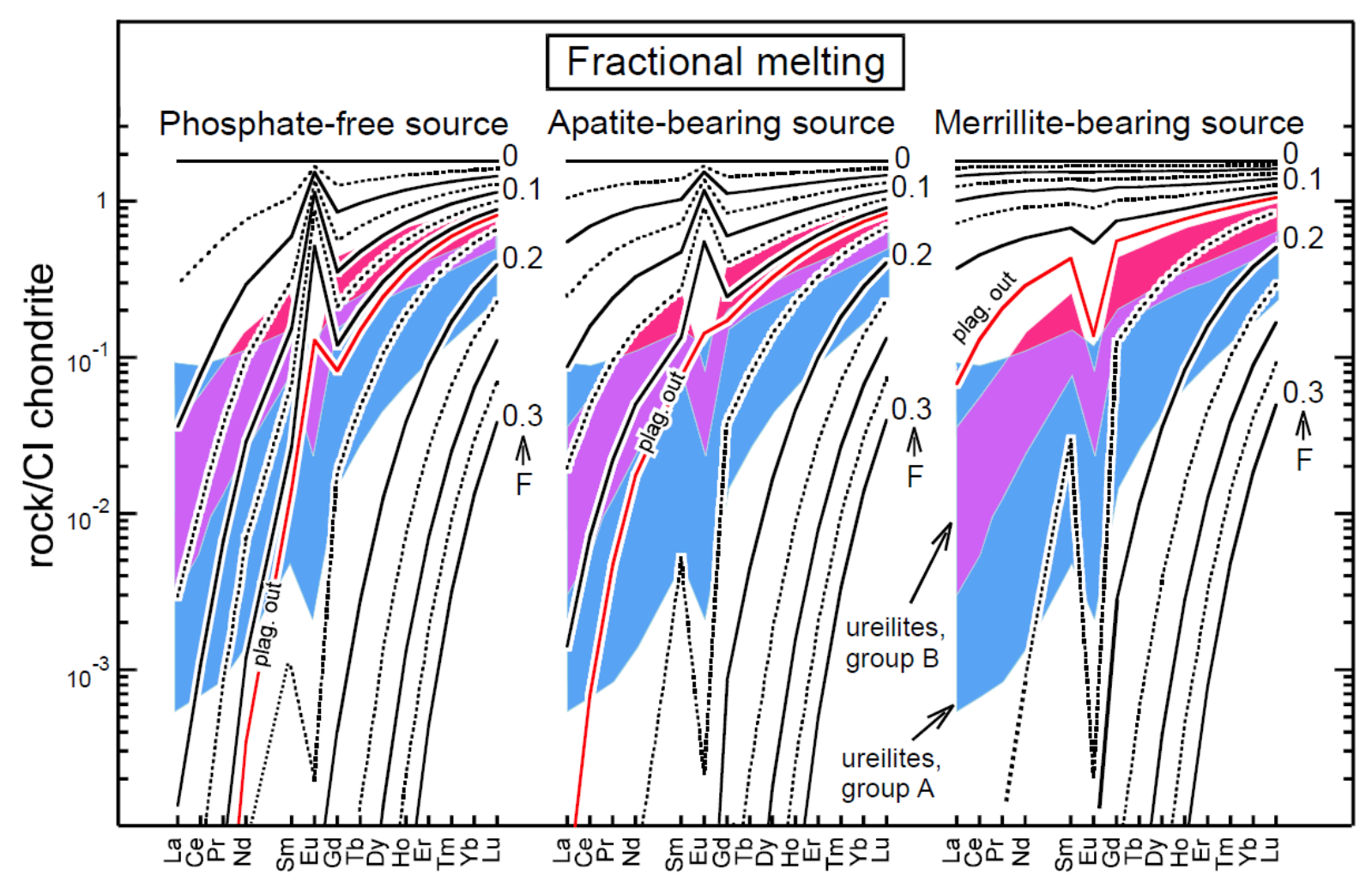

Figure 7. Results of REE modelling using three different ureilite precursors and the fractional melting law. The compositions of the sources, the melting proportions of the phases and the selected partition coefficients are given in Tables 3 and 4. The red pattern "plag. out" marks the end of the first step of silicate melting and the exhaustion of plagioclase. The fields for group A (blue) and group B (red) ureilites are shown for comparison. 


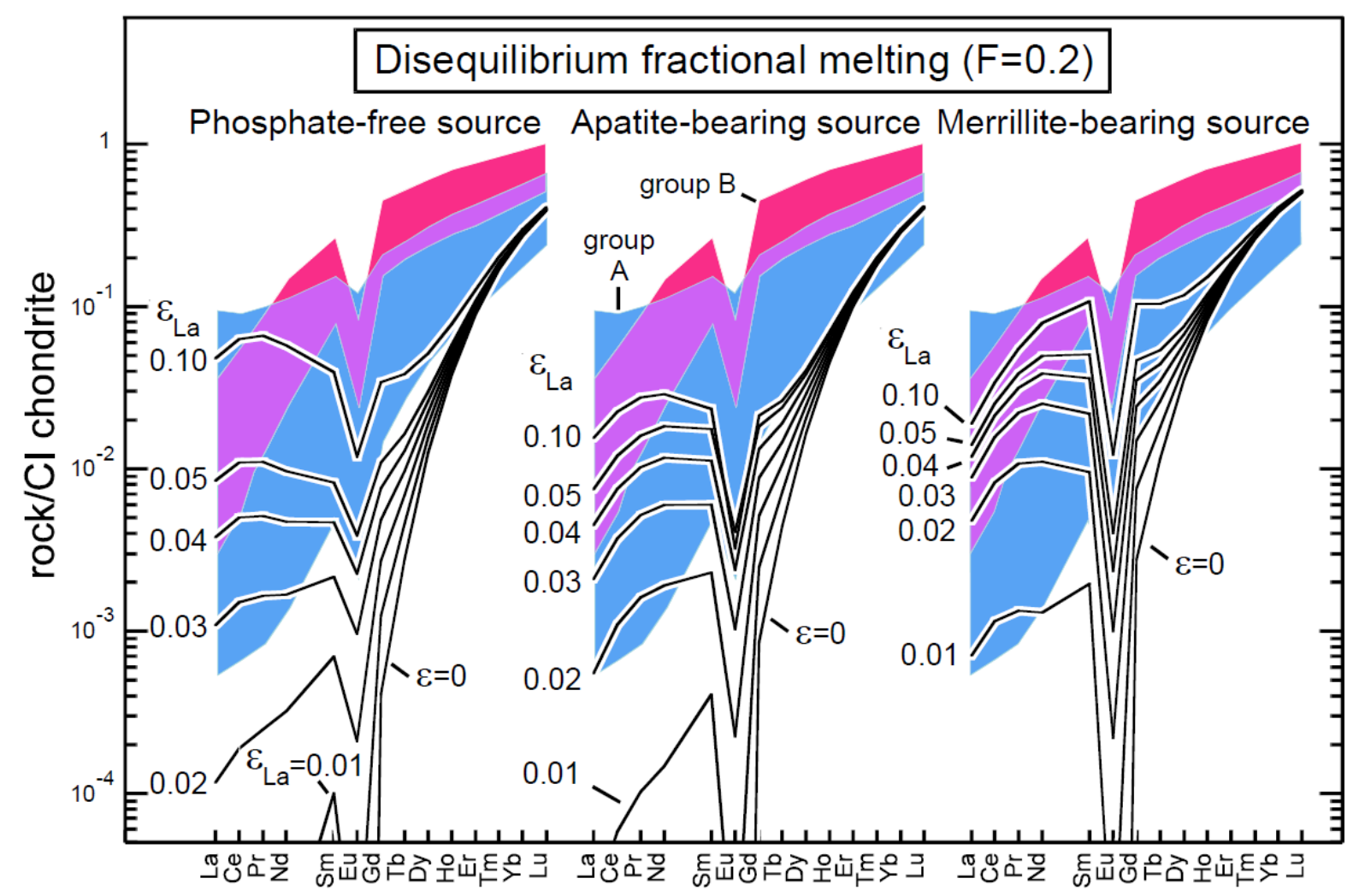

Figure 8. Results of REE modelling using three different ureilite precursors and a disequilibrium fractional melting law for $\mathrm{F}=0.2$. The compositions of the sources, the melting proportions of the phases, the selected partition coefficients and the disequilibrium parameters are given in Tables 3 and 4. The fields for group A (blue) and group B (red) ureilites are shown for comparison. 


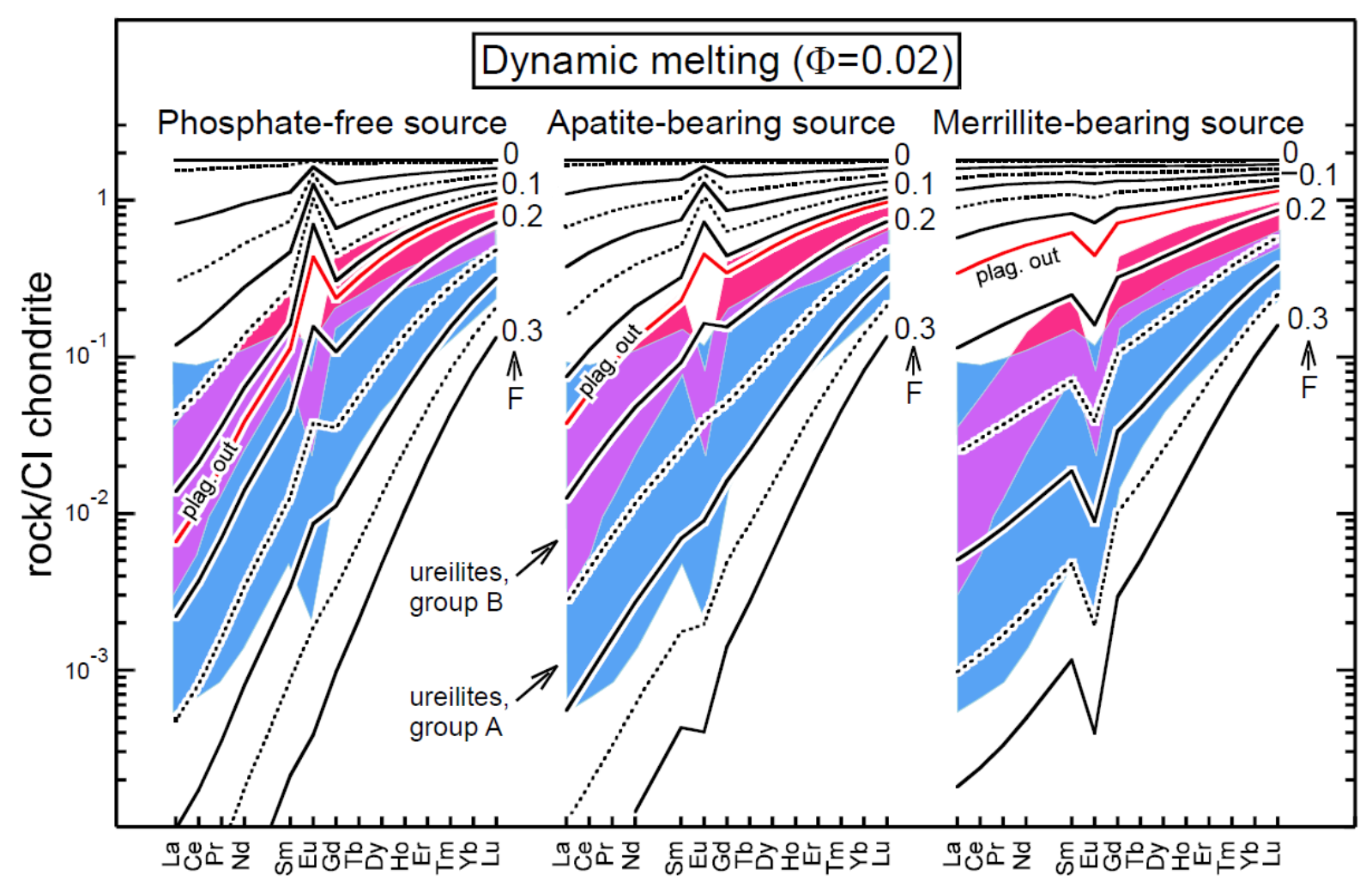

Figure 9. Results of REE modelling using three different ureilite precursors and assuming a dynamic melting model (Zou, 1998). The compositions of the sources, the melting proportions of the phases and the selected partition coefficients are given in Tables 3 and 4. The red pattern "plag. out" marks the end of the first step of silicate melting and the exhaustion of plagioclase. The fields for group A (blue) and group B (red) ureilites are shown for comparison. 


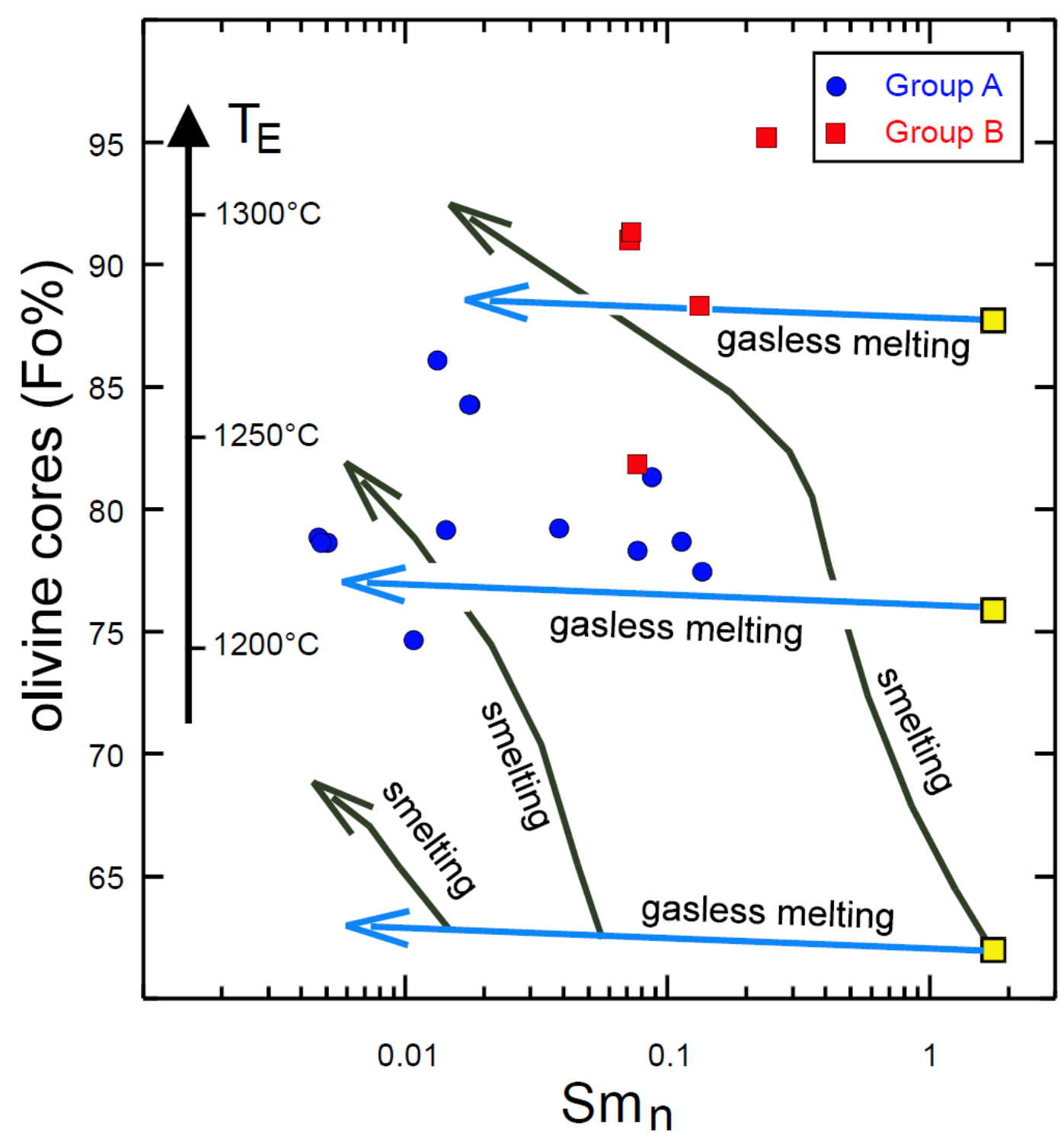

Figure 10. olivine core compositions vs. Sm abundances (normalized to $\mathrm{CI}$ ) for ureilites (leached samples). Possible melting curves for smelting and gasless melting for three different hypothetical sources are shown for comparison. The vertical black arrow shows the evolution of the temperatures of equilibrium for ureilites estimated from pigeonite compositions using the method of Singletary and Grove (2003). 